Working Paper No. 425 International transmission of shocks:

a time-varying factor-augmented VAR approach to the open economy

Philip Liu, Haroon Mumtaz and Angeliki Theophilopoulou

May 2011 


\title{
Working Paper No. 425 International transmission of shocks: a time-varying factor-augmented VAR approach to the open economy
}

\author{
Philip Liu, ${ }^{(1)}$ Haroon Mumtaz ${ }^{(2)}$ and Angeliki Theophilopoulou ${ }^{(3)}$
}

\begin{abstract}
A growing literature has documented changes to the dynamics of key macroeconomic variables in industrialised countries and highlighted the possibility that these variables may react differently to structural shocks over time. However, existing empirical work on the international transmission of shocks largely abstracts from the possibility of changes to the international transmission mechanism across time. In addition, the literature has largely employed small-scale models with limited number of variables. This paper introduces an empirical model which allows the estimation of time-varying response of a large set of domestic variables to foreign money supply, demand and supply shocks. The key results show that a foreign monetary policy tightening resembles the classic beggar-thy-neighbour scenario for the United Kingdom in the period 1975-90. In more recent periods, the response is negative but largely insignificant.
\end{abstract}

Key words: Factor-augmented VAR, time-variation, Gibbs sampling.

(1) International Monetary Fund. Email: pliu@imf.org

(2) Bank of England, Centre for Central Banking Studies. Email: haroon.mumtaz@bankofengland.co.uk

(3) University of Westminister. Email: a.theophilopoulou@westminster.ac.uk

The views expressed in this paper are those of the authors, and not necessarily those of the Bank of England. The authors wish to thank Simon Price and Paulet Sadler for useful comments. Emelie Jensert provided excellent research assistance. This paper was finalised on 31 December 2010.

The Bank of England's working paper series is externally refereed.

Information on the Bank's working paper series can be found at www.bankofengland.co.uk/publications/workingpapers/index.htm

Publications Group, Bank of England, Threadneedle Street, London, EC2R 8AH

Telephone +44 (0)207601 4030 Fax +44 (0)2076013298 email mapublications@bankofengland.co.uk 


\section{Contents}

$\begin{array}{ll}\text { Summary } & 3\end{array}$

1 Introduction $\quad 5$

2 An open economy FAVAR model with time-varying coefficients $\quad 7$

$\begin{array}{lll}2.1 \text { Estimation } & 10\end{array}$

$\begin{array}{lll}2.2 & \text { Identification of structural shocks } & 11\end{array}$

$\begin{array}{lll}2.3 \text { Data description } & 12\end{array}$

3 Empirical results 13

$\begin{array}{lll}3.1 & \text { International comovements } & 13\end{array}$

3.2 An unanticipated increase in world interest rates 15

3.3 International demand and supply shocks 22

3.4 Forecast error variance decomposition 23

4 Conclusions 28

$\begin{array}{ll}\text { Appendix } & 29\end{array}$

The empirical model 29

$\begin{array}{ll}\text { Identification } & 32\end{array}$

Estimation: multi-step Gibbs sampling 33

Imposing the sign restrictions

Generalised impulse response functions $\quad 37$

$\begin{array}{ll}\text { Description of the data } & 38\end{array}$

$\begin{array}{ll}\text { MCMC convergence diagnostics } & 40\end{array}$

$\begin{array}{ll}\text { References } & 41\end{array}$ 


\section{Summary}

Understanding and quantifying the international transmission mechanism whereby economic shocks are propagated around economies is important for formulating possible policy responses to developments in the world economy. This is one of the reasons why a substantial empirical literature has focused on this issue. But the existing work on this issue shares two shortcomings. First, analyses do not allow for the possibility of time-variation in the parameters of the model. This feature is surprising as changing dynamics of variables such as inflation and output have been highlighted by many studies of macroeconomies. Second, most empirical studies on the international transmission of shocks are based on small-scale vector autoregressions (VARs) (models that relate each variable in the system to past values of all included variables). Arguably, central banks across the world monitor (and possibly respond to) a far wider information set than is typically assumed in these small VARs, leaving them open to the possibility of misspecification. Moreover, from a practical perspective small VARs are unable to provide inference on a large number of variables that may be of interest to policy makers.

The aim of this paper is to fill these gaps in the empirical literature on international transmission. We attempt to do this by devising an empirical model that: allows for time-variation in the international transmission mechanism; and allows the simultaneous estimation of the response of a large set of UK variables to foreign monetary policy, demand and supply shocks. In particular, this paper proposes an open economy factor-augmented VAR (a FAVAR) which incorporates time-varying coefficients. This captures the widely accepted idea that most macroeconomic variables can be thought of as being largely driven by a small number of common factors. Those included in our proposed FAVAR can be thought of as weighted averages of a large panel of international and UK data. Consequently the proposed model contains significantly more information than the small-scale VARs used in the existing literature.

The empirical results, using quarterly data from 1974 to 2005, indicate that there have been important changes across time in the response of UK variables to international shocks. For example, while real activity responded strongly to foreign money expansion during the 1970s, this response was muted during the period 1992-2005. These results are consistent with a fall in the degree of exchange rate pass-through to import prices. Foreign aggregate demand shocks had 
a large positive impact on UK GDP during the years 1980-90. However, the impact over the subsequent period was substantially smaller. Foreign supply shocks had a persistent impact on UK inflation and wages during the mid-1970s, but with a smaller impact estimated during the period 1990-2005. 


\section{Introduction}

Understanding the international transmission mechanism of economic shocks is an important step towards identifying the best policy response in an individual economy to international developments. In a world economy, which has experienced a steady increase in integration across goods, capital and financial markets, the international aspect of the transmission mechanism has become an essential ingredient in policy discussions.

A large empirical literature has investigated the international transmission of monetary and non-monetary shocks using small-scale structural vector auto-regression (VAR) models. The identification restrictions in these models are often a controversial topic, where different assumptions can lead to quite different conclusions. Several recent papers have proposed alternative identification structures including, among others, the recursive schemes in Grilli and Roubini (1995), Eichenbaum and Evans (1995) and Faust and Rogers (2003), the non-recursive schemes in Cushman and Zha (1997), Dungey and Pagan (2000), Kim and Roubini (2000), and Kim (2001), and the sign restrictions in Canova (2005), Scholl and Uhlig (2006) and Liu (2008).

Despite the different approaches to identification, these papers share two important features. First, these papers do not allow for the possibility of time-variation in the coefficients and variances of the model. This feature is surprising especially as an important empirical regularity observed since the mid-1980s is the change in macroeconomic dynamics. Kim and Nelson (1999), McConnell and Perez-Quiros (2000), and Cogley and Sargent (2005) show that the volatility of US output and the volatility and persistence of US inflation has fallen significantly over the last three decades. Benati (2006) presents similar results for the United Kingdom. In addition, Cogley and Sargent (2002) and Clarida, Galí and Gertler (2000) show that changing macroeconomic dynamics in the United States were accompanied by a change in the monetary policy rule adopted by the Federal Reserve, with a higher weight given to inflation in the post-1982 period. A related strand of this literature has focused on the possibility of changes in the domestic transmission of monetary policy. Boivin and Giannoni (2006) estimate the response of output and inflation to a monetary policy shock in the United States using a VAR based on two subsamples: 1959-79 and 1980-2002. Their results suggest that the response of output and inflation is smaller in the latter period. The recent work by Campa and Goldberg (2005) provides some evidence of decline in the pass-through of exchange rate shocks to import prices for OECD 
countries. Taken together, this growing literature provides strong evidence that structural changes have occurred in prominent industrialised countries over the last 30 years. The implications of these changes for the international transmission mechanism remains largely unexplored.

Second, most empirical studies on the international transmission of shocks are based on VAR models that include only a few selected variables. Arguably, central banks across the world monitor (and possibly respond to) a far wider information set than typically assumed in these small-scale VARs leaving them open to the possibility of misspecification. Moreover, from a practical perspective small-scale VARs are unable to provide inference on large number of variables that may be of interest. For example, little or no evidence exists on the transmission of foreign shocks to domestic asset prices such as house prices and equity prices.

The aim of this paper is to fill these gaps in the empirical literature on international transmission. In particular, this paper aims to provide a comprehensive analysis of how the impact of foreign shocks on key macroeconomic variables of a small open economy like the United Kingdom has evolved over time.

We attempt to do this by devising an empirical model that: (a) allows for time-variation in the international transmission mechanism, and (b) allows the simultaneous estimation of the response of a large set of UK variables to foreign monetary policy, demand and supply shocks. In particular, this paper proposes an open economy factor-augmented VAR (FAVAR) which incorporates time-varying coefficients and stochastic volatility in the shocks. The proposed model captures the changing comovements among macroeconomic time series by allowing their dependence on common factors to evolve over time.

The main contribution of the paper is to assess possible changes to the transmission of external monetary policy, demand and supply shocks, a feature that, to the best of our knowledge, has been ignored in the literature on international transmission and the 'Great Moderation'. A further advantage of our approach is that it allows us to simultaneously derive the (time-varying) dynamic responses for a wider range of economic indicators without placing overly restrictive prior restrictions on the model's parameters.

The main results of the paper are as follows. A foreign monetary policy contraction has 
substantially different effects on the United Kingdom in the period after 1990 compared to the period 1975-90. In particular, the response of the domestic economy in the period before 1990 resembles a classic beggar-thy-neighbour scenario, with decreases in foreign money supply resulting in an increase in UK real activity. In contrast, the post-1990 period is characterised with negative but insignificant response of UK real activity to a fall in foreign money supply. Our estimates are consistent with a fall in the degree of exchange rate pass-through to import prices. A foreign aggregate demand shock has a large positive impact on UK GDP during the years 1980-90. Its impact over the more recent period has been substantially smaller. Foreign supply shocks have a persistent impact on UK inflation and wages during the mid-1970s with a smaller impact estimated during the current period.

The paper is organised as follows. Section 2 outlines the empirical model and discusses the identification assumptions. Section 3 reports the comovement of the international factors, dynamic effects of an unexpected fall in world interest rates, an unexpected increase in world activities and an unanticipated negative world supply shock on a selected subset of UK macroeconomic indicators. Section 4 contains concluding remarks and directions for future research.

\section{An open economy FAVAR model with time-varying coefficients}

We attempt to formulate an empirical model that allows us to efficiently model the relationship between a large set of UK and foreign variables, while simultaneously allowing this relationship to be time-varying. ${ }^{1}$ The starting point is the following restricted VAR model

$$
\left(\begin{array}{c}
F_{t}^{*} \\
F_{t}^{U K} \\
R_{t}
\end{array}\right)=\left[\begin{array}{ccc}
B_{11}(L) & 0 & 0 \\
B_{21}(L) & B_{22}(L) & B_{23}(L) \\
B_{31}(L) & B_{32}(L) & B_{33}(L)
\end{array}\right]\left(\begin{array}{c}
F_{t-1}^{*} \\
F_{t-1}^{U K} \\
R_{t-1}
\end{array}\right)+u_{t}
$$

The VAR in equation (1) consists of two blocks, one for the United Kingdom and other for the rest of the world, which is ordered first. ${ }^{2}$ The information about the United Kingdom and the rest of the world is summarised by the unobserved factors, $F_{t}=\left[F_{t}^{*} F_{t}^{U K}\right]^{\prime}$, where $*$ denotes the foreign economies and $U K$ denotes the domestic economy. The UK short-term interest rate, $R_{t}$,

\footnotetext{
${ }^{1}$ See the appendix for a full technical description of the model.

${ }^{2}$ The terms foreign and world are used interchangeably in this paper. The term home refers to the United Kingdom.
} 
is included to account for domestic monetary policy. The zero restrictions in equation (1) reflect our assumption that being a small open economy, the United Kingdom is unable to influence the rest of the world. ${ }^{3}$

There are three foreign factors $F_{t}^{*}=F_{t}^{Y^{*}}, F_{t}^{\pi^{*}}$ and $F_{t}^{R^{*}}$, where $F_{t}^{Y^{*}}$ is a foreign real activity factor, $F_{t}^{\pi^{*}}$ is a foreign inflation factor, $F_{t}^{R^{*}}$ is a foreign interest rate factor. $F_{t}^{U K}$ denote $k=4$ factors for the United Kingdom. The seven factors together summarise the variation in an underlying panel data set of foreign and UK variables. They are linked to the panel data set via the following equation

$$
\left(\begin{array}{c}
X_{t}^{Y^{*}} \\
X_{t}^{\pi^{*}} \\
X_{t}^{R^{*}} \\
X_{t}^{U K} \\
R_{t}
\end{array}\right)=\left[\begin{array}{ccccc}
\Lambda_{t}^{Y^{*}} & 0 & 0 & 0 & 0 \\
0 & \Lambda_{t}^{\pi^{*}} & 0 & 0 & 0 \\
0 & 0 & \Lambda_{t}^{R^{*}} & 0 & 0 \\
0 & 0 & 0 & \Lambda_{t}^{U K} & \Lambda_{t}^{R} \\
0 & 0 & 0 & 0 & 1
\end{array}\right]\left(\begin{array}{c}
F_{t}^{Y^{*}} \\
F_{t}^{\pi^{*}} \\
F_{t}^{R^{*}} \\
F_{t}^{U K} \\
R_{t}
\end{array}\right)+v_{t}
$$

where $X_{t}^{Y^{*}}$ denotes data on foreign real activity, $X_{t}^{\pi^{*}}$ denotes data on foreign inflation, $X_{t}^{R^{*}}$ denotes data on foreign interest rates and $X_{t}^{U K}$ denotes a panel data set for the United Kingdom that includes indicators on real activity, inflation, money supply and asset prices. $\Lambda_{t}^{Y^{*}}, \Lambda_{t}^{\pi^{*}}$ and $\Lambda_{t}^{R^{*}}$ are the factor loadings on foreign real activity data, foreign inflation data and foreign interest rate data. $\Lambda_{t}^{U K}$ is $N^{U K} \times k$ matrix of factor loadings that link the $k$ domestic unobserved factors to UK data and $\Lambda_{t}^{R}, N^{U K} \times 1$, captures the contemporaneous relationship between some of the 'fast-moving' UK variables (eg asset prices) and the short-term interest rate.

We assume two sources of time-variation in equations (1) and (2). Firstly, we allow the VAR covariance matrix $\operatorname{Var}\left(u_{t}\right) \equiv \Omega_{t}$ to evolve over time as a random walk. Secondly, following Del Negro and Otrok (2008), the factor loadings $\Lambda_{t}^{Y^{*}}, \Lambda_{t}^{\pi^{*}}, \Lambda_{t}^{R^{*}}, \Lambda_{t}^{U K}$ and $\Lambda_{t}^{R}$ are also assumed to evolve over time as random walks. This assumed structure is an efficient way of introducing time-varying dynamics within our model. In particular, the time-varying factor loadings allow the relationship between the foreign variables $\left(X_{t}^{Y^{*}}, X_{t}^{\pi^{*}}\right.$ and $\left.X_{t}^{\pi^{*}}\right)$ and domestic variables $X_{t}^{U K}$ to be time-varying. This can easily be seen by substituting the equation for $F_{t}^{U K}$ from (1) to the equation for $X_{t}^{U K}$ in (2). This gives $X_{t}^{U K}=\Lambda_{t}^{U K}\left[B_{21}(L) F_{t-1}^{*}+B_{22}(L) F_{t-1}^{U K}+B_{23}(L) R_{t-1}+u_{t}\right]+\Lambda_{t}^{R} R_{t}+v_{t}^{U K}$ where the product

\footnotetext{
${ }^{3}$ We expand on this in our discussion of the VAR identification scheme below.
} 
of $\Lambda_{t}^{U K} B_{21}(L)$ is time varying. Similarly, allowing $\Omega_{t}$ to be time varying implies time-varying contemporaneous relationship between foreign and domestic variables.

Equations (1) and (2) capture the time-varying dynamic relationship between macroeconomic conditions in the rest of the world (as summarised by $F_{t}^{Y^{*}}, F_{t}^{\pi^{*}}$ and $F_{t}^{R^{*}}$ ) and the UK economy (as summarised by $F_{t}^{U K}$ ). By using the VAR in equation (1) it is possible to estimate the impulse response of $F_{t}^{U K}$ to an innovation in $F_{t}^{*}$. Moreover, by using equation (2), it is possible to recover the response of any of the variables in the UK panel $X_{t}^{U K}$ to this foreign shock. Therefore, although the structure of our VAR model is similar to that in Cushman and Zha (1997) and Kim (2001), (as in Mumtaz and Surico (2009)) our specification offers the distinct advantage that the response of a wide range of UK variables to foreign shocks can easily be derived. Note also that as the factor loadings are time-varying, the impulse response of $X_{t}^{U K}$ can be estimated at each point in time over the sample period.

This model is closely related to two recent contributions in the time-varying VAR literature. Bianchi, Mumtaz and Surico (2009) estimate a time-varying (closed economy) FAVAR model where time-variation is introduced via time-varying coefficients in the VAR (ie equation (1) in our context). This approach is particularly difficult to implement within our framework because the large number of endogenous variables in (1) makes it computationally difficult to impose stability on the VAR at each point in time.

Another specification possibly suited to our problem is the elegant multi-country VAR introduced by Canova and Ciccarelli (2006). The authors introduce a VAR model of the following form

$$
Y_{i, j, t}=B Y_{i, j, t-1}+e_{t}
$$

where $i$ indexes the country and $j$ denotes the variable. The dimensions of the VAR coefficient matrix $B$ can be substantial if a large number of series/countries are included in $Y$. To deal with this problem, Canova and Ciccarelli (2006) suggest factorising the coefficients $B$ into

$$
B=\Xi K_{t}+d_{t}
$$

where $K_{t}$ is a set of factors or linear combinations of $B$ (determined by the structure of the loading matrix $\Xi$ ) that represent country-specific or variable-specific features and $d_{t}$ is an i.i.d disturbance. In this framework, time-variation can be introduced by specifying some dynamic structure for $K_{t}$. 
To see the link between this specification and our model, substitute equation (4) into (3) such that $Y_{i, j, t}=\Xi K_{t} Y_{i, j, t-1}+d_{t} Y_{i, j, t-1}+e_{t}$. Note that $\Xi Y_{i, j, t-1}$ represent linear combinations of the data analogous to the factors in a FAVAR (see equation (2)). The model in (3) has the advantage that it retains data for each country (in the panel individually) and allows the investigation of links between specific countries. However, its applicability is less clear in our context where interest centres on the influence of foreign shocks (without necessarily specifying the source of the shock as coming from a particular country). Also coefficient factorisation in equation (4) makes it difficult to directly impose restrictions implied by the small open economy assumption.

\subsection{Estimation}

The model in equations (1) to (2) is estimated using Bayesian methods described in Kim and Nelson (1998), Primiceri (2005) and Del Negro and Otrok (2008) to approximate the posterior distribution. Essentially, this amounts to reducing a complex problem of sampling from the joint posterior distribution into a sequence of tractable ones by sampling from the conditional distribution of a subset of parameters conditional on all other parameters of the model. The multi-step Gibbs sampling procedure can be broken down into four main steps (see the appendix for full details on the conditional posterior distributions).

Step 1 Conditional on all other parameters, the VAR coefficients have a normal posterior distribution where the mean and variance of this distribution can be derived via the Kalman filter (this is needed as the VAR covariance is time-varying). We impose the small open economy restrictions as a tight prior centred on zero on the appropriate elements of the VAR coefficient matrix.

Step 2 The unobserved factors can be sampled using the methods described in Carter and Kohn (1994).

Step 3 Similarly the methods for state-space models in Carter and Kohn (1994) are used to sample the time-varying factor loadings.

Step 4 We use the methods described in Primiceri (2005) and Jacquier, Polson and Rossi (1994) to sample the time-varying VAR covariance matrix. 
Our algorithm cycles through these steps 50,000 times using the last 1,000 draws for inference. The recursive means of the retained draws show little variation thus providing evidence in favour of convergence (see supplementary material in the appendix).

\section{$2.2 \quad$ Identification of structural shocks}

We are interested in studying the dynamic effects of three shocks on the UK economy: an unanticipated fall in the interest rates in the rest of the world, an unanticipated expansion in international activity and a negative world supply shock. Note that the analysis of these shocks is important from a theoretical and policy point of view. For example, a key question in international macroeconomics is the impact of external monetary shocks to a small open economy with different assumptions about pricing behaviour implying a potentially different impact on domestic variables. Using our model one can approach this question in a framework that is flexible (ie allows the impact of the shock to be time-varying) and potentially robust to misspecification due to the data-rich nature of the model (see Mumtaz and Surico (2009)). Second the impact of these shocks is policy relevant. The recent recession has been characterised by a reduction in interest rates by a large group of countries (in particular by most of the countries included in the foreign block of our model). Similarly, several previous economic events can be characterised as common demand or supply shocks abroad.

In our model, these foreign shocks are identified using two schemes based on a mixture of sign and zero restrictions and a recursive scheme. The ordering of the FAVAR is $\left[F_{t}^{Y^{*}}, F_{t}^{\pi^{*}}, F_{t}^{R^{*}}, F_{j, t}^{U K}, R_{t}\right]$ with $j=1, \ldots, k$ and the letters denote international real activity growth, inflation and interest rates, domestic factors and domestic short-term interest rate, respectively.

In our benchmark identification scheme, we impose a mixture of sign and zero restrictions:

$$
\left(\begin{array}{c}
u_{\Delta Y *} \\
u_{\Pi *} \\
u_{R *} \\
u_{F, u k} \\
u_{R}
\end{array}\right)=\left[\begin{array}{ccccc}
+ & + & - & 0 & 0 \\
+ & - & - & 0 & 0 \\
+ & \times & + & 0 & 0 \\
\times & \times & \times & \times & \times \\
\times & \times & \times & \times & \times
\end{array}\right]\left(\begin{array}{c}
e_{A D *} \\
e_{A S *} \\
e_{R *} \\
e_{F, u k} \\
e_{R}
\end{array}\right)
$$


where $e_{t}$ are the structural shocks and the sign restrictions are imposed as described in the appendix. In the foreign block, a shock to aggregate demand is associated, on impact, with an increase in foreign activity, inflation and interest rates; a positive supply shock implies a fall in inflation and a rise in real activity, the interest rate response is left unrestricted; a positive shock to the short-term interest rates comes with a decline in real activity and inflation. Notice that the impact of international shocks on the domestic economy is left unrestricted. ${ }^{4}$

We check our results using an alternative identification scheme based on a Choleski decomposition. This implies the following contemporaneous restrictions:

$$
\left(\begin{array}{c}
u_{\Delta Y *} \\
u_{\Pi *} \\
u_{R *} \\
u_{F, u k} \\
u_{R}
\end{array}\right)=\left[\begin{array}{ccccc}
\times & 0 & 0 & 0 & 0 \\
\times & \times & 0 & 0 & 0 \\
\times & \times & \times & 0 & 0 \\
\times & \times & \times & \times & \times \\
\times & \times & \times & \times & \times
\end{array}\right]\left(\begin{array}{c}
e_{\Delta Y *} \\
e_{\Pi *} \\
e_{R *} \\
e_{F, u k} \\
e_{R}
\end{array}\right)
$$

Note that by placing the UK short-term interest rate last, we implicitly identify a UK monetary policy shock under both schemes. Also, the zero restrictions in both identification schemes combined with the block-zero structure for the lag polynomial matrix $B(L)$ implies that the rest of the world does not react to UK domestic conditions contemporaneously or with lags.

\subsection{Data description}

We use quarterly data from 1974 Q1 to 2005 Q1. ${ }^{5}$ The data set spans 17 countries and 560 series. We refer to the United Kingdom as the 'domestic' economy. The 'foreign' countries are Australia, Belgium, Canada, Finland, France, Germany, Italy, Japan, Luxembourg, Netherlands, New Zealand, Norway, Portugal, Spain, Sweden and United States. The foreign block includes most of the United Kingdom's main trading partners and the major industrialised economies across the world.

For each 'foreign' country, we collect data on real activity, inflation and interest rates. For real activity, we consider data on output growth, employment, consumption and investment. Inflation

\footnotetext{
${ }^{4} \mathrm{~A}$ mixture of sign and zero restrictions is also used by Faust and Rogers (2003).

${ }^{5}$ The latest period is excluded as real activity data for some countries included in our panel was unavailable during these years. To balance the panel we restrict attention to the period 1974 Q1 to 2005 Q1.
} 
is measured on the basis of a variety of domestic price indices, wage growth and import prices. Short-term interest rates are collected for each country.

The data set for the United Kingdom is very similar in composition to that of the 'foreign block'. In particular, we have many different real activity indicators, inflation series including components of the retail price index, narrow and broad money and a set of asset prices that include house prices and the effective exchange rate. A more detailed description of the data series is available upon request (see supplementary material in the appendix).

\section{Empirical results}

This section describes the empirical results of the time-varying open economy FAVAR developed in Section 2. We report estimates of the unobserved foreign factors and compute the dynamic effects of an unanticipated increase in world interest rates, an unanticipated expansion of international activity and an unanticipated negative world supply shock using the generalised impulse response functions described in the appendix. We also compute the forecast variance decomposition of key UK variables in response to the three foreign shocks.

It is interesting to note that with a large information set, the Choleski and the sign restriction identification schemes no longer produce significantly different results. Here, we focus the discussion of the results based on the sign-restriction scheme.

\subsection{International comovements}

We extract three common components from the foreign block of the panel using the identification described above. All variables are standardised. Chart 1 plots the estimated factors for world real activity, inflation and nominal interest rates (blue is the estimated factors from the Gibbs sampling and magenta is the principal component estimator). The narrowness of the confidence interval indicates that the factors are estimated quite precisely.

It is interesting to note the similarities between the Gibbs sampling (GS) procedure and the principal components estimator (PCE) for the real activity and inflation factors. For the interest rate factor, the PCE is more persistent and the cyclical fluctuations are less volatile compared 


\section{Chart 1: Standardised foreign factors (light blue band is the $95 \%$ confidence intervals)}
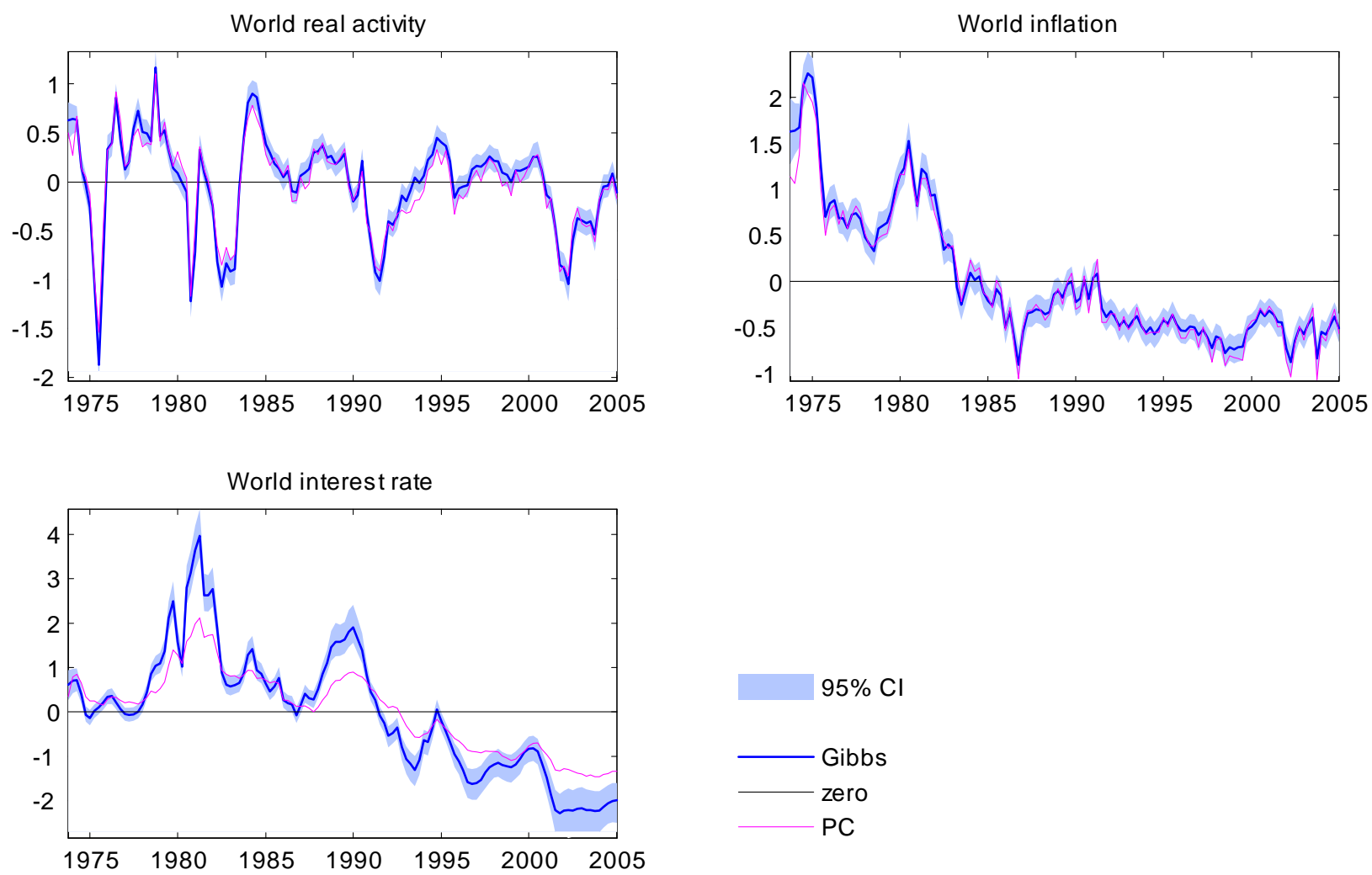

with the GS procedure. Nevertheless, the cyclical fluctuations between the two series are similar. One explanation for the difference is that the GS procedure takes into account the autocorrelation of the idiosyncratic components of each series, therefore it attributes less of the observed persistence to the common component.

Comparing our estimates with previous studies such as Kose, Otrok and Whiteman (2003), a few patterns are very similar. The industrialised world experienced, on average, four severe recessions over the sample period: the mid-1970s' oil price shock; the early 1980s' recession associated with the debt crisis, loose US fiscal policy and tight monetary policy to bring down inflation; the early 1990s' downturn; and the downturn in 2001 following the burst of the 'dotcom' bubble. The dates roughly match those identified in Kose et al (2003). Interestingly, by using higher frequency observations (quarterly data rather than annual), we identified the early 1980s' recession as a 'double dip' in economic activity whereas estimates from Kose et al (2003) suggest a prolonged recession. Our estimates suggest the decline in world economic activity in 
the mid-1970s was the steepest out of the four recessions, but its recovery was very rapid. The trough in the early 1980s' recession was less severe but the recovery was slower due to the higher interest rates over that period. The magnitude and the speed of recovery between the early 1990s' and 2001 recession was remarkably similar. In both cases, the fall in the interest rate may have helped to speed up the recovery.

The decline in the measure of international inflation is consistent with the notion of global disinflation put forward by Rogoff (2003). Despite the steady increase in oil and commodity prices between 2003-05, world inflation remained relatively stable. World interest rate peaked in the early 1980s, since then, it has declined significantly reaching historical lows in the very recent past.

\subsection{An unanticipated increase in world interest rates}

\subsubsection{World factors}

A shock to the world interest rate factor cannot be interpreted literally as a foreign policy shock as there is nothing such as a 'world policy maker'. However, a generalised increase in interest rates may represent a situation that requires central banks across the world to deviate from the path implied by the systematic component of their monetary policy. The global disinflation stance in the early 1980s and the recent experience of unprecedented low policy rates are examples of such events. Here, we interpret the unanticipated increase in interest rates across the world as a contractionary monetary policy shock that occurs, on average, in the foreign block.

Chart 2 plots the dynamic effects of the world factors in response to a contractionary monetary shock. The size of the shock is normalised to be a $1 \%$ increase in the world interest rate factor. The first column plots the median impulse response functions (IRFs) to the shock estimated for the fourth quarter of each year in the sample, while the second and third columns illustrate the responses in 1975 and 2004 together with the 68\% error bands (light blue band). The increase in world interest rates generates a statistically significant contraction in real world activity and inflation. More interestingly, once we control for the time-varying stochastic volatility the response of the world factors are very similar across time. The inflation response is slightly larger in the latter part of the sample but the difference is small. Based on these estimates, the 


\section{Chart 2: Response of world factors to a world monetary contraction}
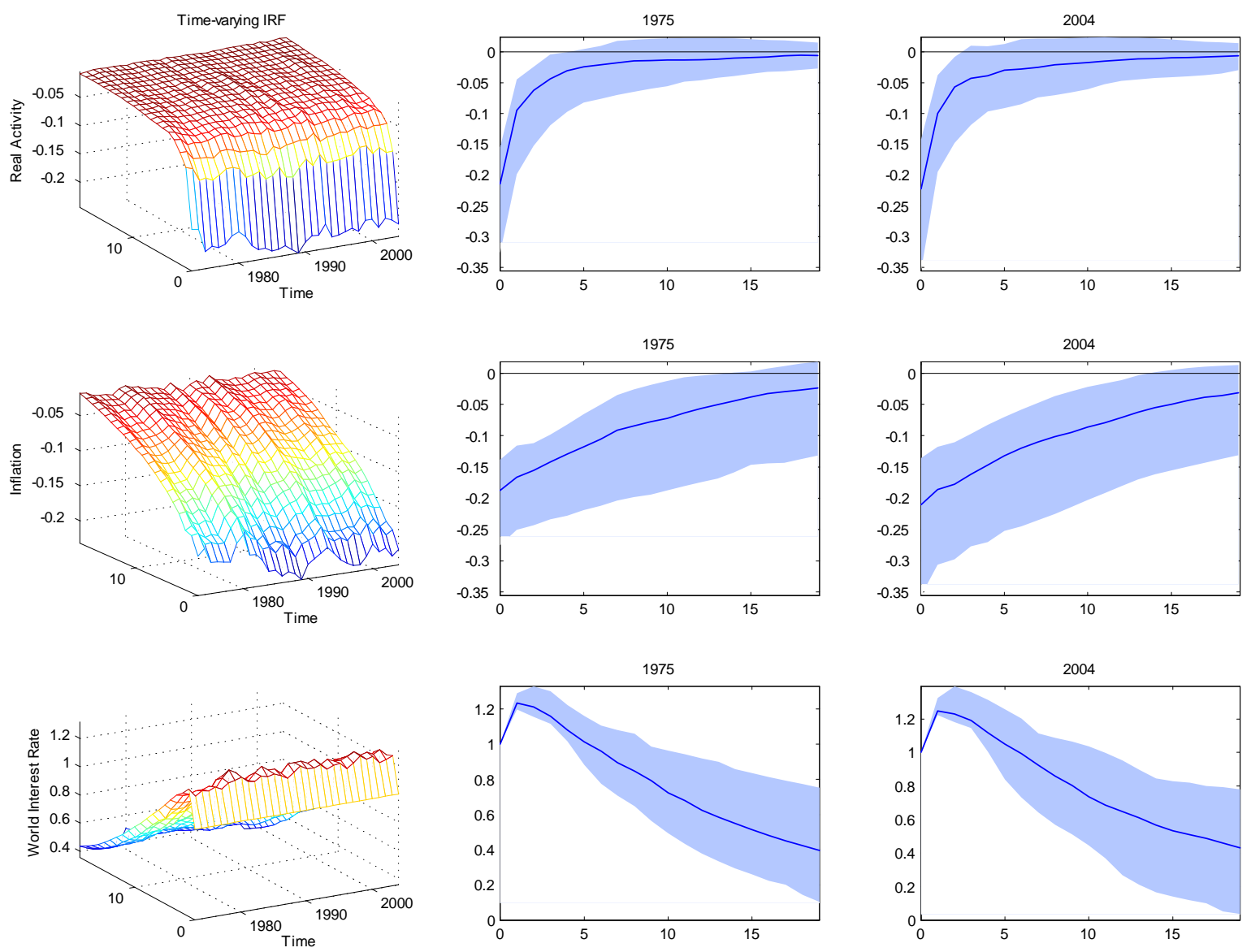

impact of world monetary policy shocks on real activity and inflation has changed little over the sample period.

\subsubsection{UK external indicators}

The key to understanding the international transmission mechanism to foreign monetary shocks rest on the behaviour of the exchange rate and the response of relative prices to the shock. Chart 3 plots the time-varying responses for the UK nominal effective exchange rate (NEER), terms of trade, trade balance, import and export prices. Note that the final column of the chart compares the distribution of impulse responses (cumulated at the one-year horizon) in 1974 and 2004. If the majority of the draws lie below the $45^{\circ}$ line, that indicates the cumulated response is larger in 
1974 relative to 2004 and vice versa. ${ }^{6}$ Throughout the sample, the exchange rate depreciates in response to higher capital outflows from the lower interest rate differential. ${ }^{7}$ Its response was the weakest in the early 1990s around the time of United Kingdom's exit from the European Exchange Rate Mechanism (ERM).

\section{Chart 3: Response of UK external indicators to a world monetary contraction}
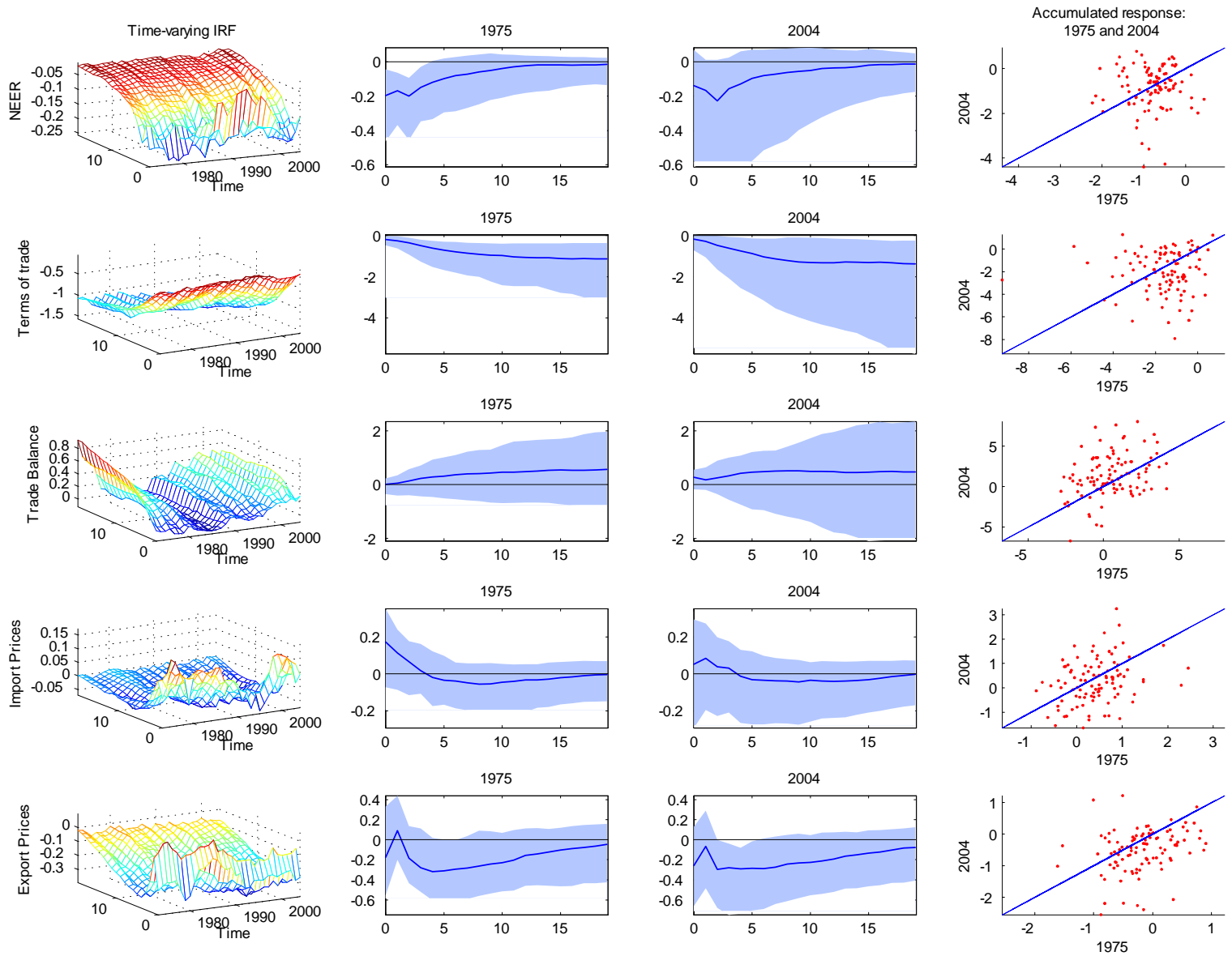

In the earlier part of the sample, the median import price response increases immediately following the exchange rate depreciation and then falls slowly. This is consistent with the notion of producer currency pricing (PCP) by foreign exporters. More recently, pass-through from the exchange rate depreciation is smaller with the median contemporaneous response closer to zero. This lends more support towards local currency pricing (LCP) and is consistent with recent papers that document a fall in exchange rate pass-through in the United Kingdom (see for

\footnotetext{
${ }^{6}$ Note that in the text, by statistical significance we imply a situation where the posterior distribution does not contain zero.

${ }^{7}$ Foreign interest rate is higher than the domestic interest rate.
} 
example Campa and Goldberg (2006) and Mumtaz, Oomen and Wang (2006)). As a result of this shock, the United Kingdom's terms of trade deteriorates and the trade balance improves with a larger response in the early years of the sample. This is consistent with the earlier explanation of PCP, high exchange rate pass-through and the classic expenditure switching effect.

\subsubsection{UK real activity and inflation}

\section{Chart 4: Response of UK real activities to a world monetary contraction}
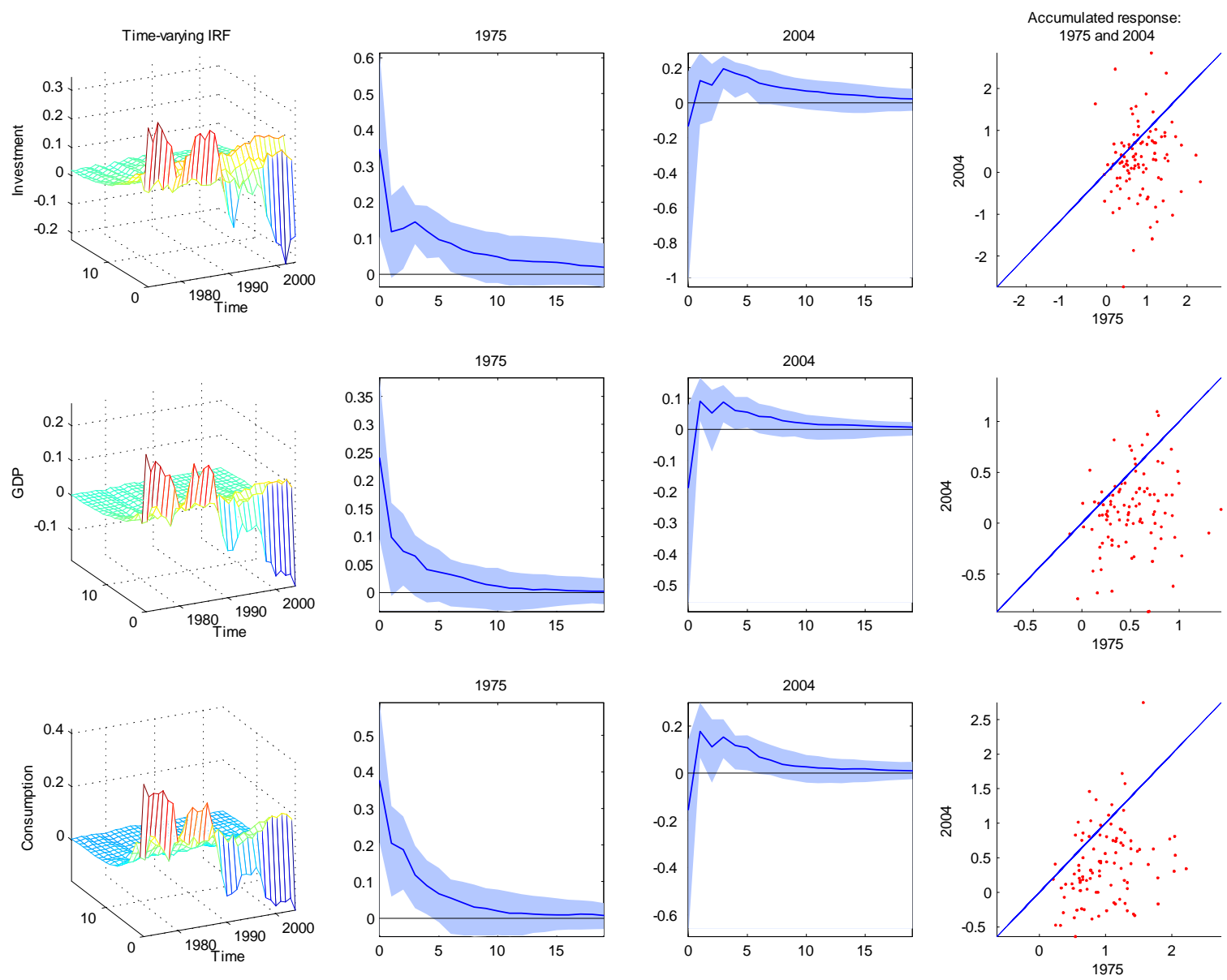

Chart 4 plots the time-varying response of investment, GDP and consumption. One striking feature is the uniform switch in the sign of contemporaneous responses from positive to negative among the real activity indicators in the early 1990s. Note also that, while the positive impact on investment, GDP and consumption is large and significant in the earlier part of the sample, the corresponding negative responses toward the end of the sample period are largely insignificant. This change is consistent with the possibility discussed above of a shift from producer to local 
currency pricing and a fall in exchange rate pass-through. Under PCP, high exchange rate pass-through to import prices give domestic consumers more incentives to shift consumption towards relatively cheaper home goods - the expenditure switching effect. If this expenditure switching effect dominates the negative income effect from the contraction in world money supply, then domestic real activity is positively affected as appears to be the case in the earlier part of the sample. On the other hand, if imports are priced in local currency and exchange rate pass-through is low, then there is less incentive for consumers to switch from imports to domestic goods and the beggar-thy-neighbour effect is ameliorated. See Betts and Devereux (1999) for a more detailed explanation. ${ }^{8}$

\section{Chart 5: Response of UK inflation and wages to a world monetary contraction}
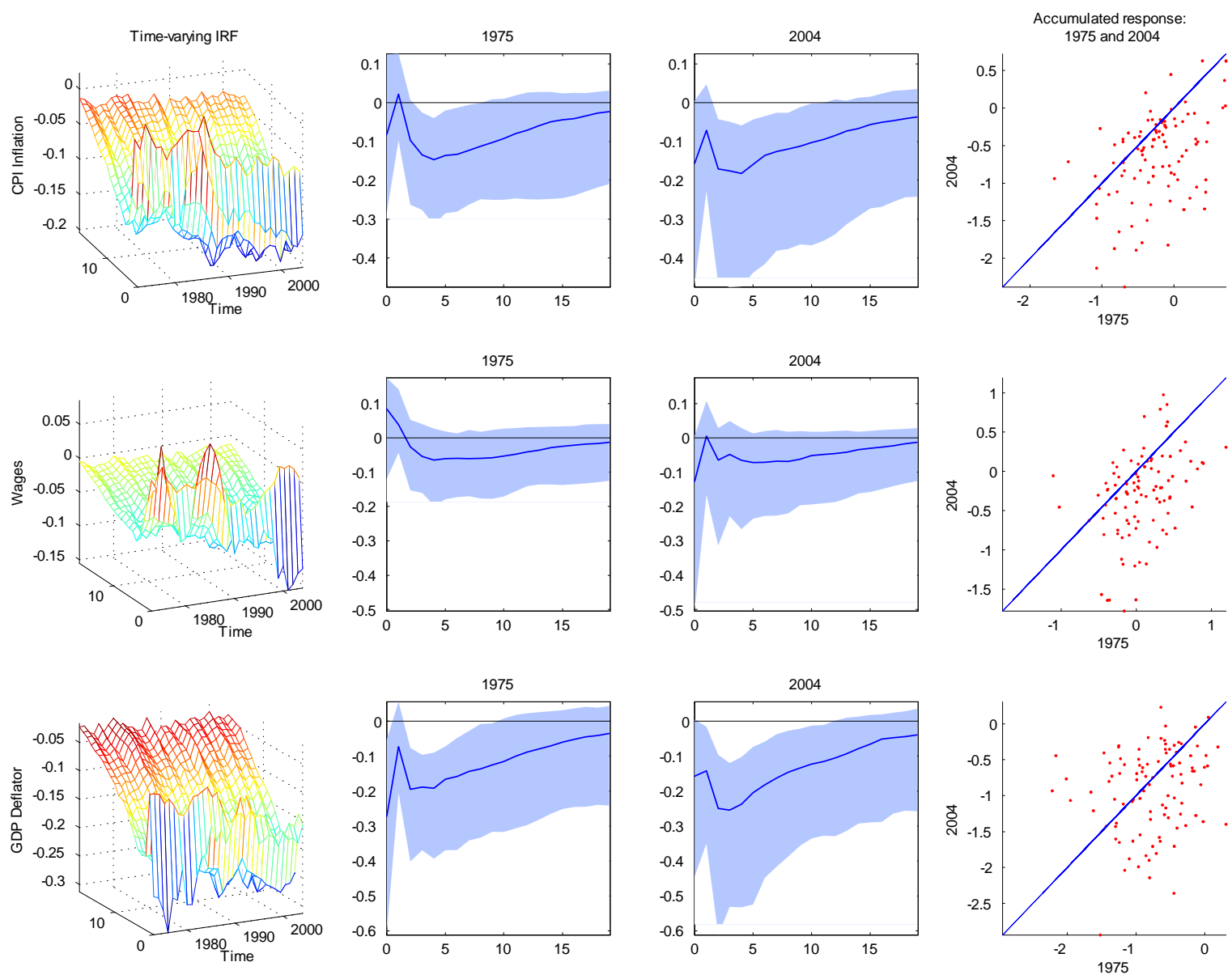

Chart 5 plots the time-varying response of nominal wages, inflation measures based on the CPI

\footnotetext{
${ }^{8}$ We have also investigated the possibility of changes to the policy stance using Lubik and Schorfheide's (2005) model as an alternative explanation. However, changes to both foreign and domestic policy stance cannot explain the switch in the sign of domestic activities.
} 
and GDP deflator. Both inflation measures fall immediately following the shock and reach their peak around four quarters. According to the CPI measure, the accumulated fall is slightly smaller in the earlier sample whereas the GDP deflator measure shows a similar response across the sample period. The wage response is largely around zero at the beginning of the sample but falls slightly in the later sample.

\subsubsection{UK asset prices}

\section{Chart 6: Response of UK asset prices to a world monetary contraction}
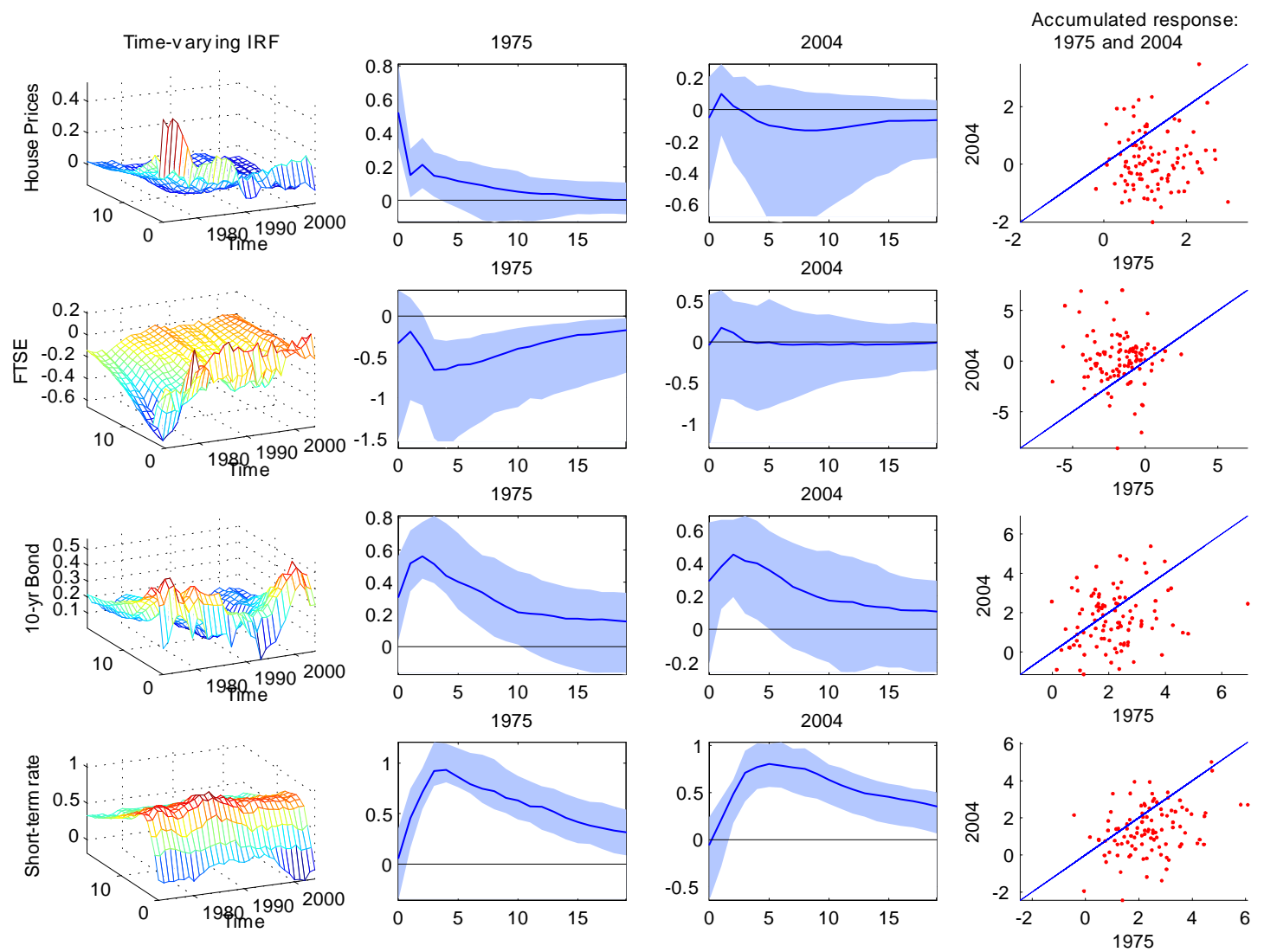

Chart 6 plots the time-varying response of 90-day, 10-year government bond yields, and the growth rate of house and equity (measured by the FTSE index) prices. There is a statistically significant increase in both the short and long-term interest rates following the shock. The response of house prices is positive and significant during the 1970s and the 1980s. However, this response is largely insignificant over the post-1990 period. The FTSE declines in response to the shock in the 1970s but its response is largely insignificant over the rest of the sample period. 


\subsubsection{Results from recursive identification scheme}

\section{Chart 7: Response of UK variables to a world monetary contraction using recursive identi- fication}
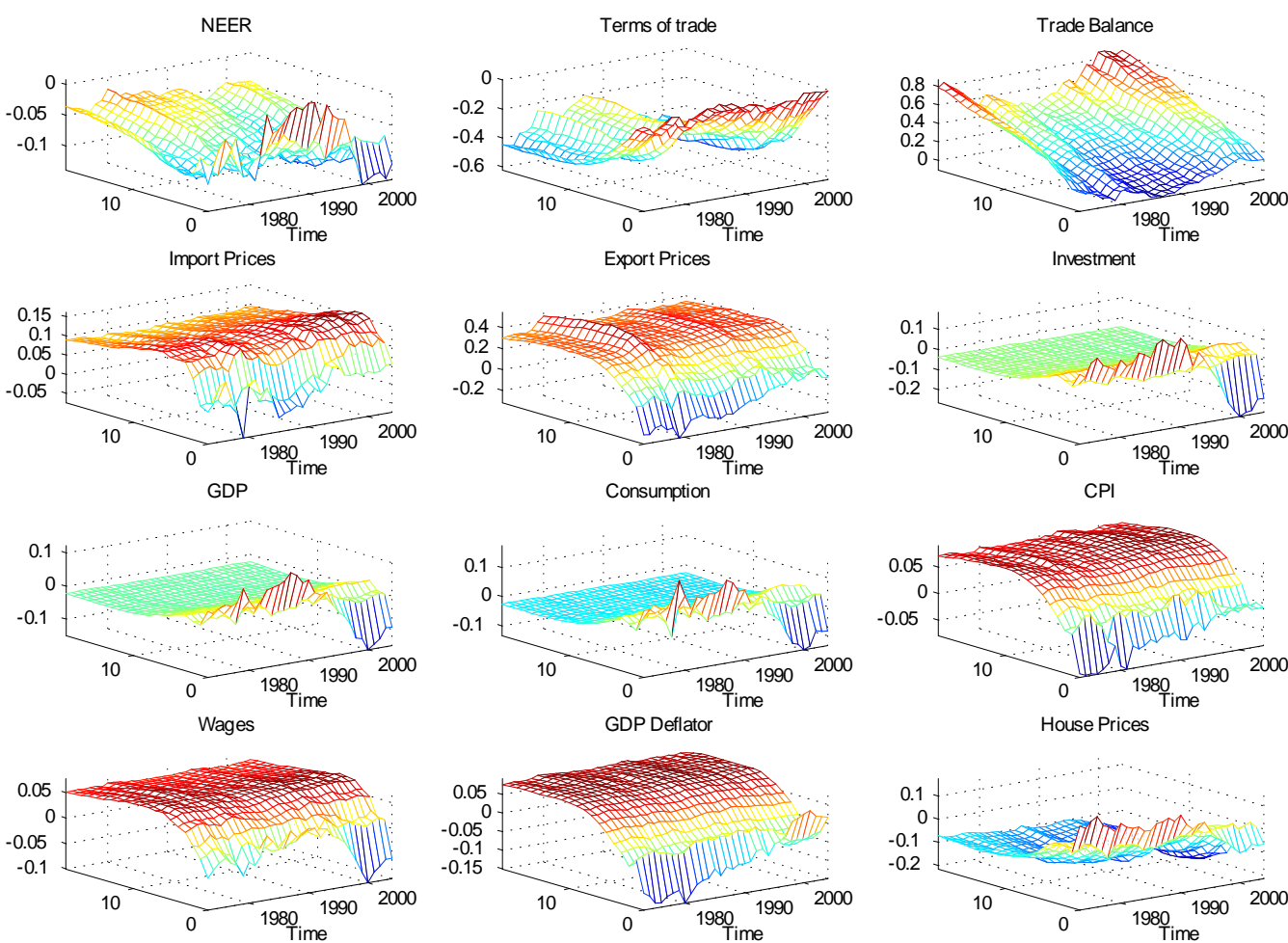

Chart 7 plots the time-varying response for various UK variables using the recursive identification scheme (RIS) described in equation (6). The sign and shape of the dynamic responses are largely similar across the two identification schemes. However, there are some interesting differences. First, the magnitude of the NEER and terms of trade responses are smaller in the RIS. For example, the terms of trade now peaks at $0.5 \%$ rather than $1.2 \%$ earlier. Second, the responses for wages and the inflation measures from the RIS returns to zero much faster, within the first five quarters of the shock rather than over 20 quarters. Third, the switch in the sign of domestic economic activity now happens in a much more gradual manner. Nevertheless, the timing of the switch are more or less the same. 


\section{Chart 8: Response of key UK variables to a positive world demand shock}
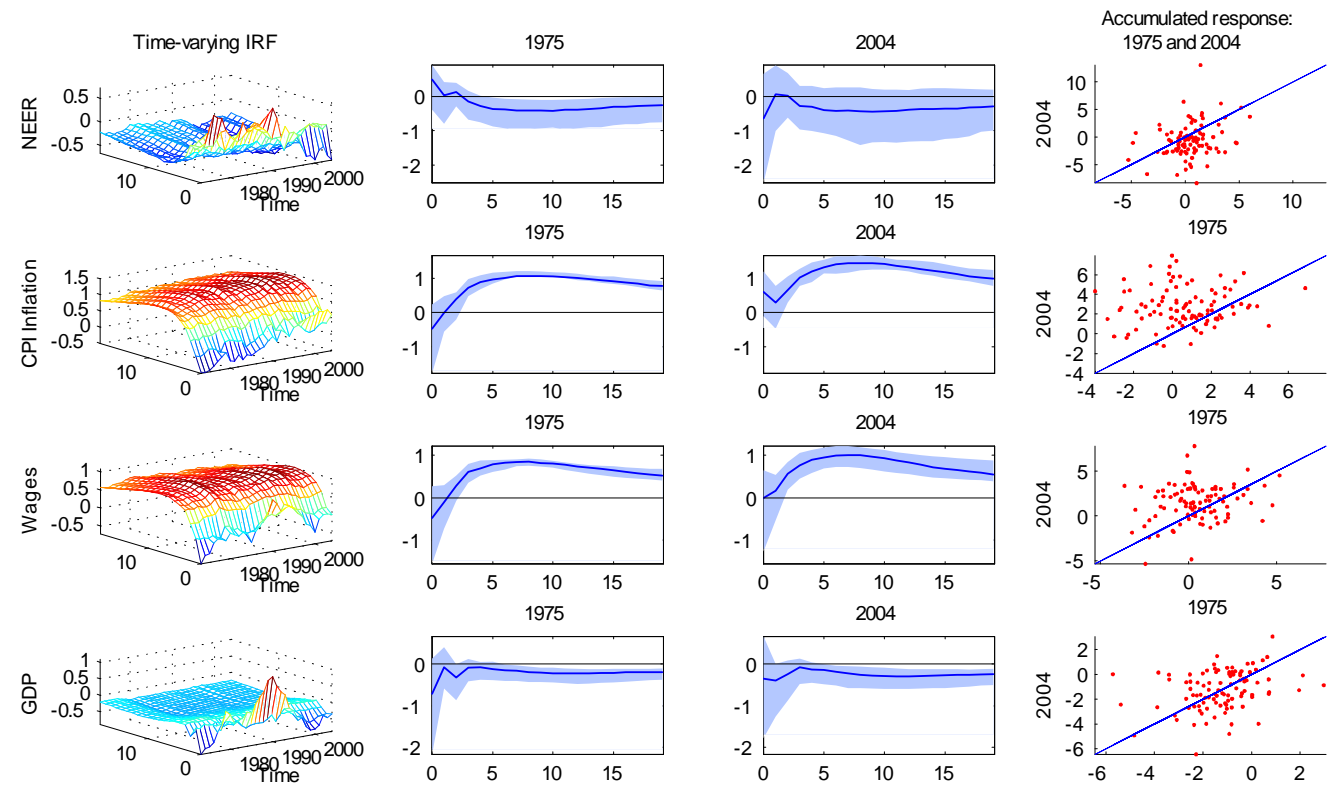

2004
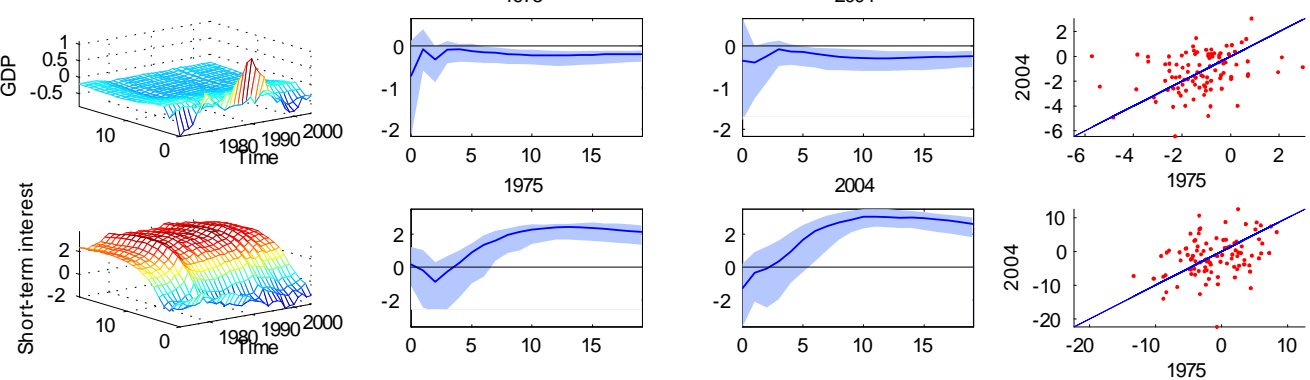

\subsection{International demand and supply shocks}

Chart 8 presents the response of key UK variables to a positive foreign demand shock. The shock is normalised so that it increases the world activity factor by one unit. ${ }^{9}$ The NEER and the terms of trade were virtually unaffected by the shock. At the beginning and the end of the sample, the impact on domestic real activity is close to zero. However, for a large part of the sample (between 1980 and 1998) domestic activity increases in response to the higher world demand albeit the impact is relatively short-lived. The strongest impact is between 1980-90. Both nominal wages and CPI inflation is significantly positive in the medium term. The peak response of the domestic short-term interest rate response to this shock is very similar across the sample.

Impulse responses to a negative world supply shock (calibrated to increase the world inflation factor by $1 \%$ ) are presented in Chart 9 . Both inflation and wages increase significantly in

\footnotetext{
${ }^{9}$ Note that the normalisation of the demand and supply shocks on real activity and inflation factors, respectively, is for convenience and simplicity. These responses could be normalised on other variables.
} 


\section{Chart 9: Response of key UK variables to a negative world supply shock}
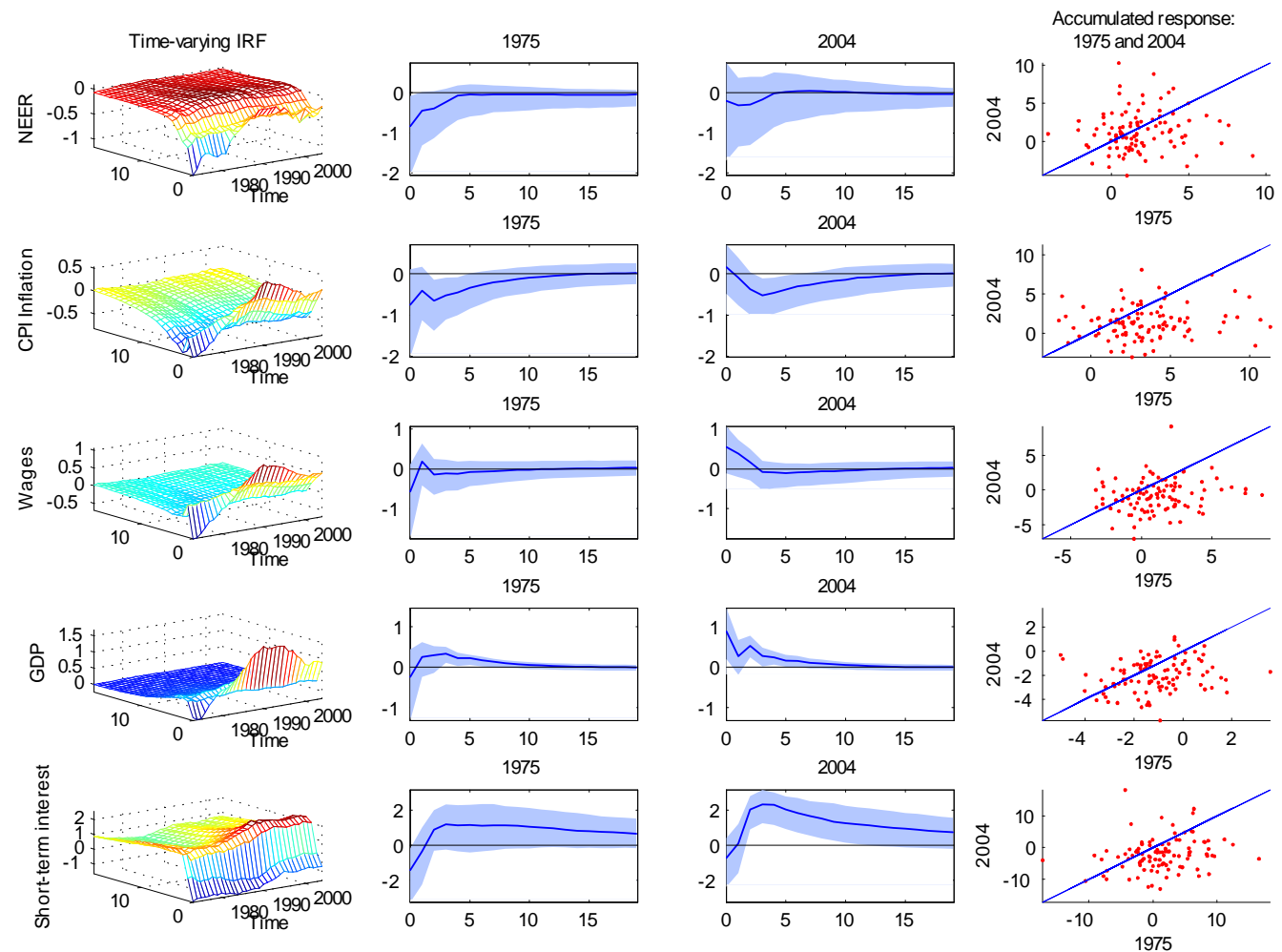

response to this shock during the 1970s. It is interesting to note that the response of these variables in the post-1980 period is smaller and less persistent, possibly indicating the role played by monetary policy in anchoring inflation expectations during the Thatcher years. UK GDP, falls following the supply shock. The magnitude of this fall is smaller since the 1990s.

\subsection{Forecast error variance decomposition}

Our model allows us to compute a time-varying forecast error variance decomposition to assess possible changes in the importance of foreign shocks for the UK economy, Chart 10 plots the decomposition (the median estimate for the fourth quarter of each year in the sample) for 'external indicators' of the United Kingdom. The three foreign shocks together contribute around $20 \%$ of the total forecast error variance for the NEER across the sample period, with foreign monetary policy shocks more important in the pre-1980 period. Foreign demand shocks appear important for import and export prices throughout the sample period, explaining about $20 \%$ to $30 \%$ of the forecast error variance. It is interesting to note that foreign supply shocks played an 


\section{Chart 10: Variance decompositions of UK external sector to foreign shocks}
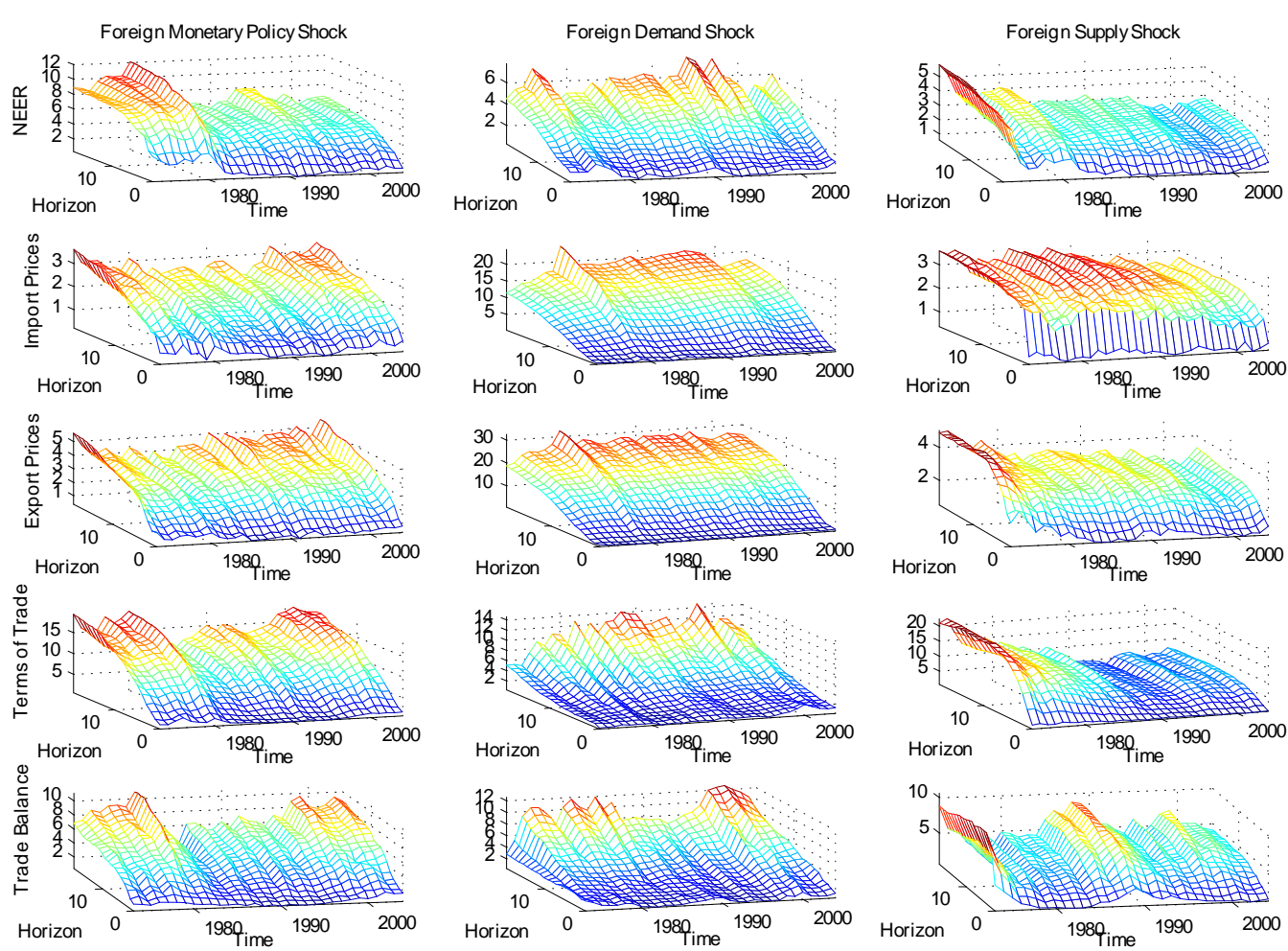

important role for the terms of trade before the 1990s but much smaller role more recently.

Chart 11 shows that the foreign shocks are estimated to have contributed around $20 \%$ of the total forecast error variance for UK real activity. The foreign monetary policy shocks were somewhat more important during the 1970s. On the other hand, supply shocks appear to have the largest contribution during the late 1980s and the early 1990s.

Chart 12 presents the forecast error variance decomposition for wages and inflation. Foreign demand shocks made an important contribution to the measures of inflation and wages throughout the sample period, contributing around $10 \%$ to $25 \%$ especially at long horizons. Foreign supply shocks were important during the 1970s especially for GDP deflator inflation.

In Chart 13, the foreign monetary policy shocks contribute around $10 \%$ to the forecast error variance of house prices during the 1970s, with a smaller contribution in the subsequent periods. More recently, foreign demand shocks have played a more important role in determining house 


\section{Chart 11: Variance decompositions of UK activity indicators to foreign shocks}
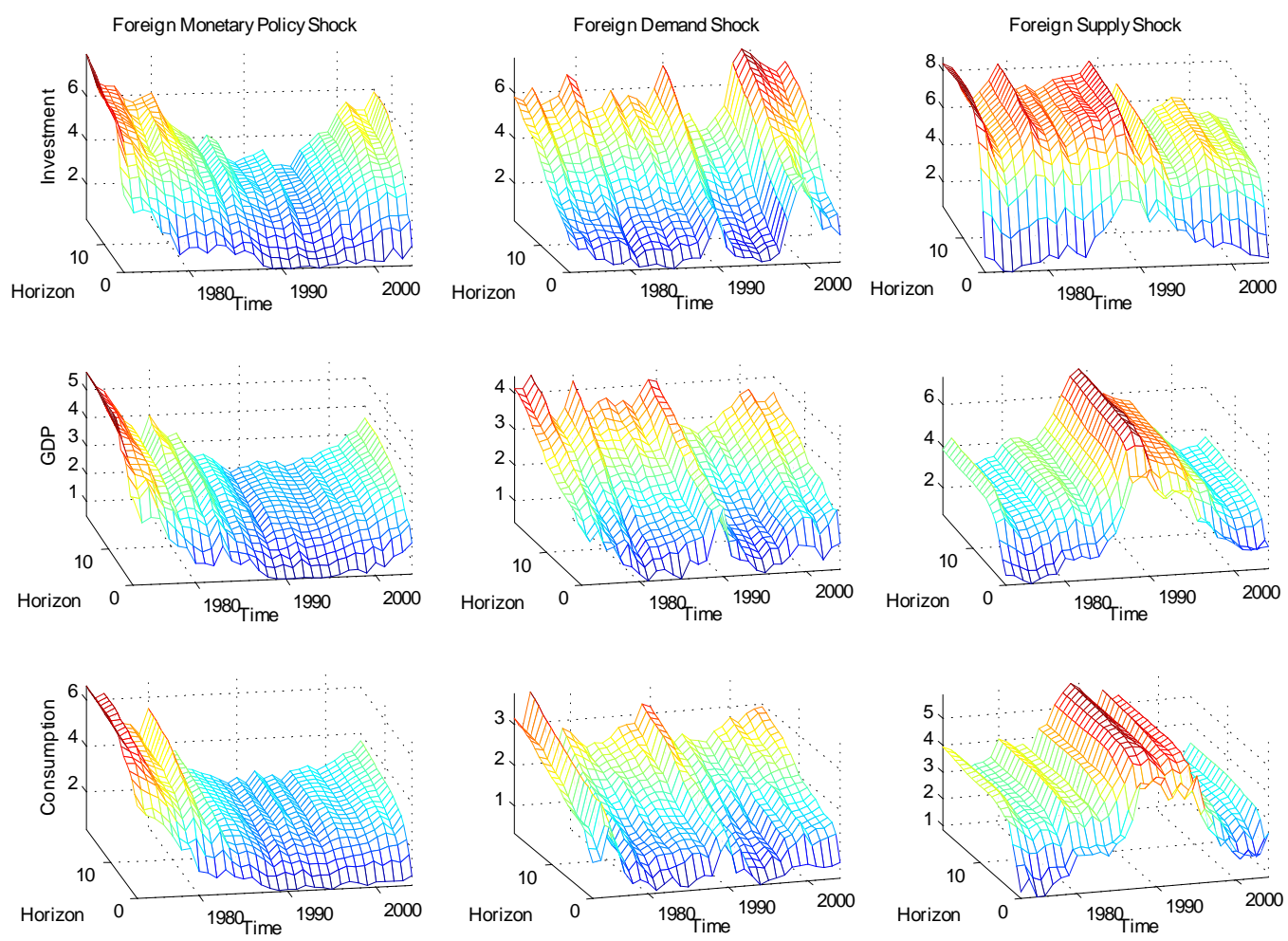

price forecast error variance. The decomposition for the FTSE shows a similar pattern, with foreign monetary policy and supply shocks relatively important during the 1970s while foreign demand shocks make a slightly larger contribution towards the end of the sample period. It is interesting to note that foreign policy shocks were important for the short-term interest rate in the pre-1990 period. However, demand shocks have remained important for the short and long-term rate over the entire sample. 


\section{Chart 12: Variance decompositions of UK inflation indicators to foreign shocks}
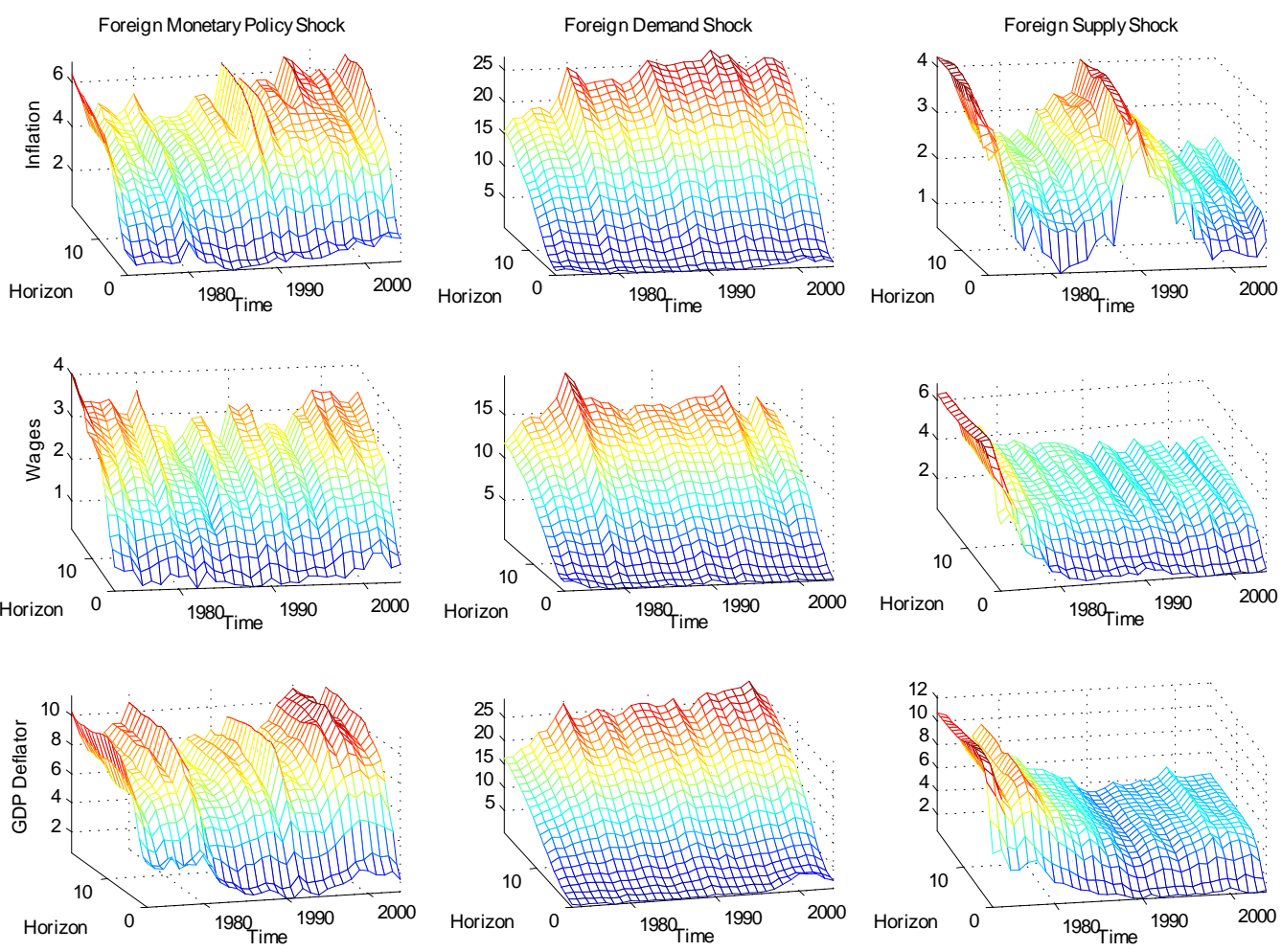


\section{Chart 13: Variance decompositions of $\mathrm{UK}$ asset indicators to foreign shocks}
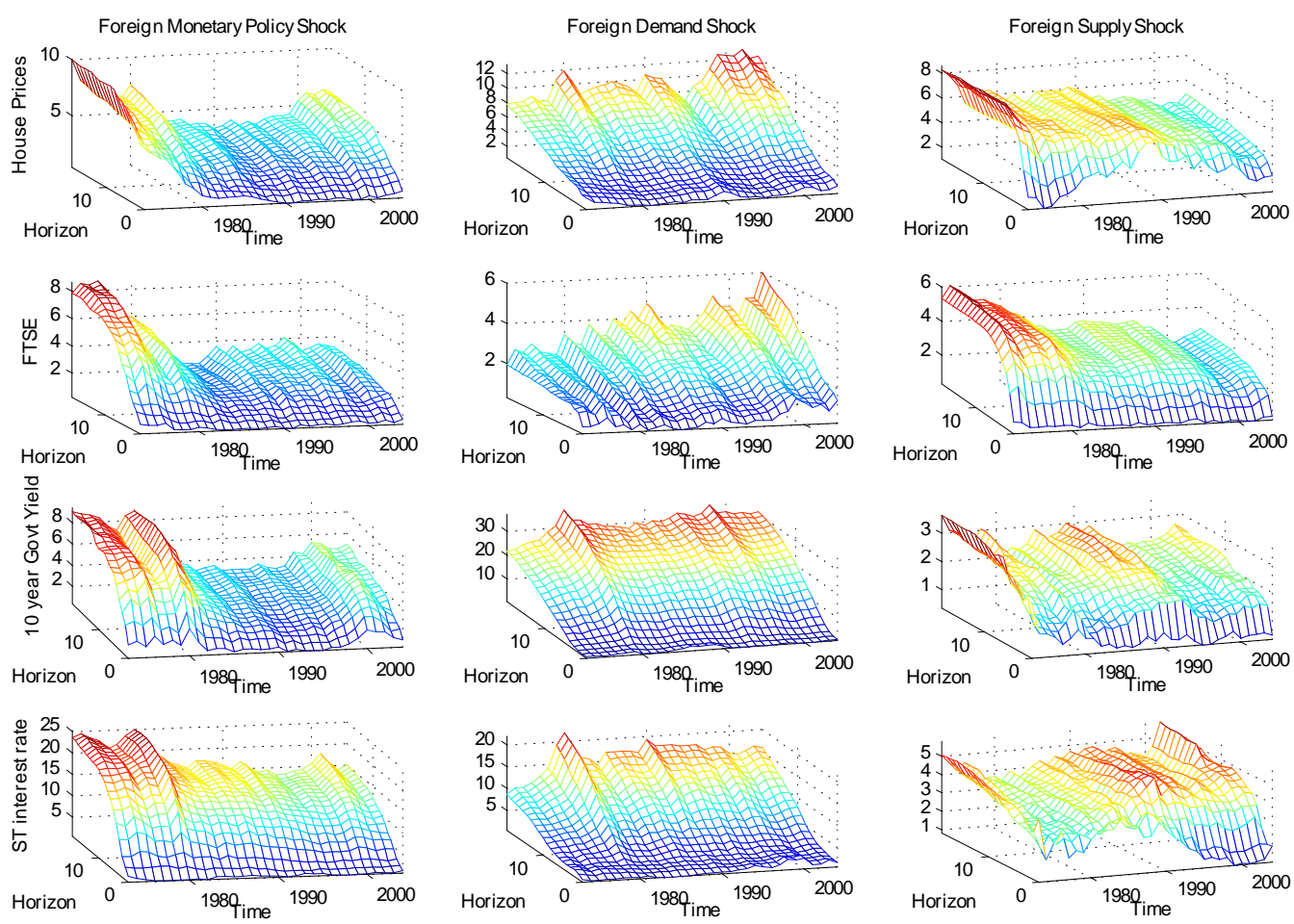


\section{Conclusions}

This paper has studied the international transmission of structural shocks in an open economy FAVAR model applied to the United Kingdom. Unlike previous contributions, we use data on 17 countries and 560 variables, covering prices, activity and monetary indicators, to model the interaction between the foreign and domestic blocks of the VAR. In addition, we allow the relationships embodied in this model to change over time by incorporating time-varying coefficients and stochastic volatility within the FAVAR framework.

A foreign monetary policy easing has substantially different effects on the United Kingdom in the period after 1990. In particular, the response of the domestic economy in the period before 1990 resembles a classic beggar-thy-neighbour scenario, with decreases in foreign money supply resulting in an increase in UK real activity. In contrast, the post-1990 period is characterised with negative but insignificant response of UK real activity to this shock. A positive foreign aggregate demand shock have a large positive impact on UK GDP during the years 1980-90. Its impact over the more recent period have been substantially smaller. Foreign supply shocks led to a persistent increase in UK inflation and wages during the 1970s, with the current impact estimated to be relatively small.

Forecast error variance decomposition from the model suggests that the contribution of foreign shocks to forecast error variance of domestic variables have been relatively modest, yet non-negligible ranging at most $40 \%$ to $50 \%$ in total for some variables. The contributions also display time-variation: the role of foreign monetary policy and supply shocks have become smaller over the sample period. In contrast, foreign demand shocks remain important for UK inflation and asset prices.

In this study, we have identified changes to the international transmission of shocks around 1990 which corresponds to significant changes to the United Kingdom's monetary policy framework. Future research could therefore be directed towards understanding the interactions between monetary policy response and the international transmission mechanism. 


\section{Appendix}

\section{The empirical model}

The model consists of two blocks, one for the United Kingdom and other for the rest of the world, which is ordered first. ${ }^{10}$ The information about the United Kingdom and the rest of the world are summarised by $K$ unobserved factors, $F_{t}=\left[F_{t}^{*} F_{t}^{U K}\right]^{\prime}$, where $*$ denotes the foreign economies and $U K$ denotes the domestic economy. The UK short-term interest rate, $R_{t}$, is the only observable factor. This together with the unobserved common components form the dynamic system that evolves according to the following transition equation:

$$
\left(\begin{array}{c}
F_{t}^{*} \\
F_{t}^{U K} \\
R_{t}
\end{array}\right)=\left[\begin{array}{ccc}
B_{11}(L) & 0 & 0 \\
B_{21}(L) & B_{22}(L) & B_{23}(L) \\
B_{31}(L) & B_{32}(L) & B_{33}(L)
\end{array}\right]\left(\begin{array}{c}
F_{t-1}^{*} \\
F_{t-1}^{U K} \\
R_{t-1}
\end{array}\right)+u_{t}
$$

where $B(L)$ is a conformable lag polynomial of finite order $p$, and $u_{t}=\Omega_{t}^{1 / 2} e_{t}$ with the structural disturbances $e_{t} \sim N(0, I)$ and $\Omega_{t}=A_{0, t}\left(A_{0, t}\right)^{\prime}$ is the stochastic covariance of the reduced form shocks. The structure of $B(L)$ reflects the small open economy assumption such that the domestic factors do not impact on world factors, but not vice versa. The time-varying covariance matrix of the VAR innovations, $u_{t}$, can be factored as

$$
\operatorname{Var}\left(u_{t}\right) \equiv \Omega_{t}=A_{t}^{-1} H_{t}\left(A_{t}^{-1}\right) \prime
$$

Following Primiceri (2005), the time-varying matrices $H_{t}$ and $A_{t}$ are defined as:

$$
H_{t}=\left[\begin{array}{cccc}
h_{1, t} & 0 & \cdots & 0 \\
0 & h_{2, t} & \ddots & \vdots \\
\vdots & \ddots & \ddots & 0 \\
0 & \cdots & 0 & h_{n, t}
\end{array}\right]
$$

\footnotetext{
${ }^{10}$ The term foreign and world are used interchangeably.
} 
and

$$
A_{t}=\left[\begin{array}{cccc}
1 & 0 & \cdots & 0 \\
\alpha_{21, t} & 1 & \ddots & \vdots \\
\vdots & \ddots & \ddots & 0 \\
\alpha_{n 1, t} & \cdots & \alpha_{n n-1, t} & 1
\end{array}\right]
$$

with $\ln h_{i, t}$, and the non-zero and non-unit elements of the matrix $A_{t}$ is assumed to evolve as driftless random walks

$$
\begin{aligned}
\ln h_{i, t} & =\ln h_{i, t-1}+\mu_{i, t}, \quad i=1, \ldots, n \\
\alpha_{i j, t} & =\alpha_{i j, t-1}+\xi_{i j, t}, \quad i=2, \ldots, n \text { and } j=1, \ldots, n-1
\end{aligned}
$$

where the distributional assumptions regarding $\left[\mu_{t}, \xi_{t}\right]$ are stated below. The random walk assumption allows for permanent shifts in the stochastic volatility terms. Allowing the simultaneous relations $\left(A_{t}\right)$ to vary over time is crucial for modelling the time-varying dynamics of structural VAR models.

The unobserved factors are extracted from a large panel of $N$ foreign and domestic indicators containing important information about the fundamentals of the economies. The factors are assumed to be related to the variables in the panel $\left(X_{t}\right)$ according to the following observation equation:

$$
\begin{aligned}
\left(\begin{array}{c}
X_{t}^{Y^{*}} \\
X_{t}^{\pi^{*}} \\
X_{t}^{R^{*}} \\
X_{t}^{U K} \\
R_{t}
\end{array}\right)=\left[\begin{array}{ccccc}
\Lambda_{t}^{Y^{*}} & 0 & 0 & 0 & 0 \\
0 & \Lambda_{t}^{\pi^{*}} & 0 & 0 & 0 \\
0 & 0 & \Lambda_{t}^{R^{*}} & 0 & 0 \\
0 & 0 & 0 & \Lambda_{t}^{U K} & \Lambda_{t}^{R} \\
0 & 0 & 0 & 0 & 1
\end{array}\right]\left(\begin{array}{c}
F_{t}^{Y^{*}} \\
F_{t}^{\pi^{*}} \\
F_{t}^{R^{*}} \\
F_{t}^{U K} \\
R_{t}
\end{array}\right)+v_{t} \\
v_{t}=\rho(L) v_{t}+\epsilon_{t}
\end{aligned}
$$

where $\Lambda_{t}^{Y^{*}}, \Lambda_{t}^{\pi^{*}}$ and $\Lambda_{t}^{R^{*}}$ are the factor loadings on foreign real activity, foreign inflation and foreign interest rates with size $N^{Y^{*}} \times 1, N^{\pi^{*}} \times 1$ and $N^{R^{*}} \times 1$ respectively; $\Lambda_{t}^{U K}$ is $N^{U K} \times k$ matrix of factor loadings for the domestic unobserved factors and $\Lambda_{t}^{R}, N^{U K} \times 1$, captures the contemporaneous relationship between the domestic indicators and the short-term interest rate; and $\epsilon_{t}$ is a $(N-1) \times 1$ vector of i.i.d disturbances. ${ }^{11}$

\footnotetext{
${ }^{11}$ The last row of equation (A-7) is an identity which does not have an error term.
} 
Following Del Negro and Otrok (2008), the factor loadings $\Lambda_{t}^{Y^{*}}, \Lambda_{t}^{\pi^{*}}, \Lambda_{t}^{R^{*}}, \Lambda_{t}^{U K}$ and $\Lambda_{t}^{R}$ are also assumed to evolve as driftless random walks

$$
\begin{gathered}
\Lambda_{t}^{Y^{*}}=\Lambda_{t-1}^{Y^{*}}+\eta_{t}^{Y^{*}} \\
\Lambda_{t}^{\pi^{*}}=\Lambda_{t-1}^{\pi^{*}}+\eta_{t}^{\pi^{*}} \\
\Lambda_{t}^{R^{*}}=\Lambda_{t-1}^{R^{*}}+\eta_{t}^{R^{*}} \\
\Lambda_{t}^{U K}=\Lambda_{t-1}^{U K}+\eta_{t}^{U K} \\
\Lambda_{t}^{R}=\Lambda_{t-1}^{R}+\eta_{t}^{R}
\end{gathered}
$$

All the innovations in the model are assumed to be jointly normally distributed with the following assumptions on the variance covariance matrix:

$$
V=\operatorname{Var}\left(\begin{array}{c}
\mu_{t} \\
\xi_{t} \\
\epsilon_{t} \\
\eta_{t}^{Y^{*}} \\
\eta_{t}^{\pi^{*}} \\
\eta_{t}^{R^{*}} \\
\eta_{t}^{U K} \\
\eta_{t}^{R}
\end{array}\right)=\left[\begin{array}{cccccccc}
W & 0 & 0 & 0 & 0 & 0 & 0 & 0 \\
0 & S & 0 & 0 & 0 & 0 & 0 & 0 \\
0 & 0 & Q & 0 & 0 & 0 & 0 & 0 \\
0 & 0 & 0 & M^{Y^{*}} & 0 & 0 & 0 & 0 \\
0 & 0 & 0 & 0 & M^{\pi^{*}} & 0 & 0 & 0 \\
0 & 0 & 0 & 0 & 0 & M^{R^{*}} & 0 & 0 \\
0 & 0 & 0 & 0 & 0 & 0 & M^{U K} & M^{U K, R} \\
0 & 0 & 0 & 0 & 0 & 0 & M^{U K, R} & M^{R}
\end{array}\right]
$$

To reduce the number of estimated parameters, we further assume the covariance matrices for the stochastic volatility $(W)$, the off-diagonal non-zero elements $(S)$ and the idiosyncratic error terms in the observation equation $(Q)$ are diagonal. However, we allow for correlations between the factor loadings in each equation but not across equations. In principle, one can allow for a much richer covariance structure among the innovations in the system. Nevertheless, there are at least two reasons in favour of the simplified structure described in (A-14). First, the high number of parameters in the system will require specifying sensible priors to prevent cases of ill-determined parameters. Second, as highlighted in Del Negro and Otrok (2008), a completely generic covariance structure will complicate the structural interpretation of the innovations.

The system (A-1)-(A-14) is the FAVAR model proposed by Bernanke, Boivin and Eliasz (2005) and extended to the open economy by Mumtaz and Surico (2008). The main innovation in this paper is the introduction of time-varying factor loadings and stochastic volatilities. This is 
important in order to examine changes to the international transmission mechanism.

\section{Identification}

\section{Unobserved factors}

There are three factors for the rest of the world representing international comovements in real activity, inflation and short-term interest rates. The international factors are identified through the upper $\left(N^{Y^{*}}+N^{\pi^{*}}+N^{R^{*}}\right) \times 3$ block of the matrix in (A-7). We assume that all real activity series in the foreign block of the model share common dynamics and that such common dynamics are not shared by any other series in the panel. The international real activity factor is identified as the only factor that is loaded by all real activity series in the rest of the world. Similar restrictions are assumed for the international inflation and short-term interest rate factors.

The dynamics of the UK variables are captured by $k$ UK factors, where $k$ is assumed to be four. The UK factors are not identified in a sense that they are extracted from the full panel of UK series. The sub-matrix $\Lambda_{t}^{U K}$ in (A-7) is a full matrix with the normalisation assumption on the first $k$ series. The reason for leaving the domestic factor loadings unrestricted is that the dynamics of the variables in $X_{t}^{U K}$ will depend on the structure imposed on the loadings. For example, if all domestic activity series share a single domestic activity factor, then the response of all domestic activity indicators will also share the common dynamics up to a scale factor pinned down by the loading. One of the goals of this paper is to investigate any possible heterogeneity in the responses of domestic prices and activities across sectors, and therefore it is unsatisfactory to impose a tight constraint on the dynamics of the individual series. The vector $\Lambda_{t}^{R}$, measuring the contemporaneous relationship between the domestic indicators and the short-term interest rate is also left unrestricted.

The identification scheme described above imposes most of the structure on the foreign block while leaving the domestic block, whose responses is the object of investigation, relatively unconstrained. The dynamics of each domestic series is a linear combination of all UK factors and the domestic short-term interest rate. The transition equation (A-1) links the dynamic responses between the international and domestic factors. Together with the identification restrictions discussed in the next subsection, the international factors serve to identify the foreign 
shocks.

\section{Estimation: multi-step Gibbs sampling}

The model in equations (A-1) to (A-14) is estimated using procedures described in Kim and Nelson (1998), Primiceri (2005) and Del Negro and Otrok (2008) to approximate the posterior distribution. Essentially, this amounts to reducing a complex problem of sampling from the joint posterior distribution into a sequence of tractable ones by sampling from the conditional distribution of a subset of parameters conditional on all other parameters of the model. The multi-step Gibbs sampling procedure can be broken down to five main blocks.

\section{Time-invariant parameters}

We initialise the factors using a simple principal component estimator. Given the values for the factors $F_{t}$, the time-varying factor loadings $\Lambda_{t}$, the stochastic volatilities $H_{t}$ and the off-diagonal covariances $A_{t}$, we can then draw the time-invariant parameters for the VAR coefficients $B(L)$, the autoregressive coefficients of the error term in observation equation $\rho(L)$ and the hyperparameter $Q$.

Drawing the VAR coefficients is complicated by the presence of heteroscedasticity in the VAR covariance. We derive the conditional posterior distribution of the VAR coefficients by rewriting the VAR as state-space system and the parameters are drawn using the algorithm described in Carter and Kohn (1994):

$$
\begin{aligned}
F_{t} & =B_{t}(L) F_{t-1}+u_{t} \\
B_{t}(L) & =B_{t-1}(L)
\end{aligned}
$$

where $B_{t}(L)$ is assumed to be time-invariant and the covariance of $u_{t}$ is $\Omega_{t}$. Note that the restrictions implied by the small open economy assumption are incorporated by using an appropriate prior distribution for $B_{t}(L)$ :

$$
p(B(L)) \sim N\left(B_{0}, \Omega_{0}\right)
$$

where $B_{0}$ has all elements equal to zero except those corresponding to the first lagged dependent variables which are set equal to the autocorrelation coefficient obtained via univariate 
autoregressions on the initial value of $F_{t}$. The values of $\Omega_{0}$ are chosen such that they imply a very strong prior belief that the elements in the top block of $B(L)$ in equation (A-1) equal zero.

For the autoregressive coefficients $(\rho(L))$ of the error term in equation (A-8), the conditional posterior distribution is easy to derive. To keep the notation simple, we write down the case where $L=1$. Conditional on the factors $\left(F_{t}\right)$ and the factor loadings $\left(\Lambda_{t}\right)$, the errors in the measurement equation are independent across each equation $i$. We can draw $\rho$ from its conditional posterior distribution given $Q$

$$
\rho \mid Q \sim N\left(\rho_{1}, \Sigma_{1}\right)
$$

where $\rho_{1}=\left(\Sigma_{0}^{-1}+Q^{-2} v_{t-1}^{\prime} v_{t-1}\right)^{-1}\left(\Sigma_{0}^{-1} \rho_{0}+Q^{-2} v_{t-1}^{\prime} v_{t}\right)$ and $\Sigma_{1}=\left(\Sigma_{0}^{-1}+Q^{-2} v_{t-1}^{\prime} v_{t-1}\right)^{-1}$. We assume that the prior mean $\rho_{0}=0$ and the prior variance $\Sigma_{0}=1$. Given $\rho$, we then draw the hyperparameter $Q$ from an inverse Gamma distribution $I G\left(\frac{a_{1}}{2}, \frac{\delta_{1}}{2}\right)$, where $a_{1}=a_{0}+T$ and $\delta_{1}=\delta_{0}+\left(v_{t}-\rho v_{t-1}\right)^{\prime}\left(v_{t}-\rho v_{t-1}\right){ }^{12}$

\section{Unobserved factors}

In the second block of the Gibbs sampling, we draw the factors conditional on all other parameters of the model. Rewriting the state and observation equation in (A-1) and (A-7) in compact form:

$$
\begin{aligned}
& F_{t}=B_{t}(L) F_{t-1}+u_{t} \\
& X_{t}=\Lambda_{t} F_{t}+v_{t}
\end{aligned}
$$

Since $v_{t}$ is assumed to be autocorrelated, we rewrite (A-19) as

$$
\begin{aligned}
(I-\rho(L)) X_{t} & =(I-\rho(L)) \Lambda_{t} F_{t}+\epsilon_{t} \\
X_{t}^{*} & =\Lambda_{t}^{*} F_{t}+\epsilon_{t}
\end{aligned}
$$

The measurement errors $\boldsymbol{\epsilon}_{t}$ in (A-21) are now i.i.d $N(0, Q)$. Equations (A-18) and (A-21) give the standard Kalman filter system. We can now apply Carter and Kohn's (1994) procedure to the above system to calculate $F_{t}$. The distribution of the factors $F_{t}$ is linear and Gaussian:

$$
\begin{aligned}
& F_{T} \backslash \Upsilon \sim N\left(F_{t \mid T}, V_{t \mid T}\right) \\
& F_{t \mid} \backslash F_{t+1}, \Upsilon \sim N\left(F_{t \backslash t+1, F_{t+1}}, V_{t \backslash t+1, F_{t+1}}\right)
\end{aligned}
$$

\footnotetext{
${ }^{12} a_{0}$ and $\delta_{0}$ are the prior shape and scale parameter of the inverse Gamma distribution.
} 
where $\Upsilon$ represent all other parameters in the model, $t=T-1, . .1$, and:

$$
\begin{aligned}
F_{T \backslash T} & =E\left(F_{T} \backslash \Upsilon\right) \\
V_{T \backslash T} & =\operatorname{Cov}\left(F_{T} \backslash \Upsilon\right) \\
F_{t \backslash t+1, F_{t+1}} & =E\left(F_{t} \backslash \Upsilon\right) \\
V_{t \backslash t+1, F_{t+1}} & =\operatorname{Cov}\left(F_{t} \backslash \Upsilon\right)
\end{aligned}
$$

As shown by Carter and Kohn (1994) the simulation proceeds as follows. First we use the Kalman filter to draw $F_{T \backslash T}$ and $V_{T \backslash T}$ and then proceed backwards in time using:

$$
\begin{aligned}
& F_{t \mid t+1}=F_{t \mid t}+V_{t \mid t} V_{t+1 \mid t}^{-1}\left(F_{t+1}-F_{t}\right) \\
& V_{t \mid t+1}=V_{t \mid t}-V_{t \mid t} V_{t+1 \mid t}^{-1} V_{t \mid t}
\end{aligned}
$$

Time-varying factor loadings

Conditional on the factors $\left(F_{t}\right)$, the errors in the measurement equation are independent across $i$. This implies the innovations in equation (A-8) are also independent across $i$. Consequently, we can draw the time-varying factor loadings one equation at a time. We apply the same transformation to the measurement equation as before which gives

$$
\begin{aligned}
(I-\rho(L)) X_{t} & =(I-\rho(L)) \Lambda_{t} F_{t}+\epsilon_{t} \\
X_{t}^{*} & =\Lambda_{t} F_{t}^{*}+\epsilon_{t} \\
\Lambda_{t} & =\Lambda_{t-1}+\eta_{t}
\end{aligned}
$$

where the variance of $\eta_{t}$ is block diagonal, that is the factor loadings are independent across equations but correlated within the same equation. For the $i^{t h}$ equation $\eta_{t}^{i} \sim N\left(0, M^{i}\right)$. Using equation (A-27) together with the law of motion for $\Lambda_{t}$ in (A-29) allows us to draw the time-varying factor loadings $\left(\Lambda_{t}\right)$ using the Carter and Kohn's (1994) algorithm from its conditional distribution $N\left(\Lambda_{t \mid T}^{*}, V_{t \mid T}^{\Lambda^{*}}\right)$. The hyperparameters for the variance of $\eta_{t}, M$, are drawn from an inverse Wishart distribution.

Following Del Negro and Otrok (2008) we add an additional step in the sampler to estimate the initial condition $\Lambda_{0}$. Starting from a prior for $\Lambda_{0} \sim N\left(\bar{\Lambda}_{0}, \bar{V}_{0}\right)$ obtained via OLS regressions on 
the pre-sample, we obtain the posterior estimate of $\Lambda_{0}$ by updating the mean and variance $\bar{\Lambda}_{0}$ and $\bar{V}_{0}$ using the methods described in Carter and Kohn (1994).

Given a draw for $\Lambda_{t}$, we then draw the hyperparameter $M^{i}$ from an inverse Wishart distribution with a scale parameter $\eta_{t}^{i \prime} \eta_{t}^{i}+\delta_{0}^{M^{i}}$ and degrees of freedom given by sample size. We set the prior scale parameter $\delta_{0}^{M}$ as $1 \times 10^{-3}$.

Time-varying simultaneous relations:

Given the factors $\left(F_{t}\right)$, the VAR coefficients $(B(L))$ and stochastic volatility terms $\left(H_{t}\right)$, we can draw the time-varying simultaneous relations $\left(A_{t}\right)$. Let $\alpha_{t}$ be the vector of non-zero and non unit elements of the matrix $A_{t}$ (stacked by rows). One can rewrite the VAR model in (A-1) as

$$
A_{t}\left(F_{t}-B(L) F_{t}\right)=A_{t} \hat{F}_{t}=H_{t} e_{t}
$$

Taking $B(L)$ as given, $\hat{F}_{t}$ is computable. Since $A_{t}$ is a lower triangular matrix, (A-30) can be written as

$$
\hat{F}_{t}=Z_{t} \alpha_{t}+H_{t} e_{t}
$$

where $Z_{t}$ is the following $n \times \frac{n(n-1)}{2}$ matrix

$$
Z_{t}=\left[\begin{array}{cccc}
0 & \cdots & \cdots & 0 \\
-\hat{F}_{1, t} & 0 & \cdots & 0 \\
0 & -\hat{F}_{[1,2], t} & \ddots & \vdots \\
\vdots & \ddots & \ddots & 0 \\
0 & \cdots & 0 & -\hat{F}_{[1, \ldots, n-1], t}
\end{array}\right]
$$

and $\hat{F}_{[1, \ldots, i], t}$ denotes the row vector of $\left[\hat{F}_{1, t}, \hat{F}_{2, t}, \ldots, \hat{F}_{i, t}\right]$. Intuitively, equation (A-31) is equivalent to regressing the error term of the VAR on other error terms according to the lower triangular structure. With the block diagonal assumption of $S$, this allows us to apply the standard state-space method with stochastic volatility as described in Carter and Kohn (1994).

\section{Stochastic volatility}

Similarly, we can rewrite the VAR model in (A-1) as

$$
A_{t}\left(F_{t}-B(L) F_{t}\right)=F_{t}^{*}=H_{t} e_{t}
$$


Given $B(L)$ and $A_{t}, F_{t}^{*}$ are observed. Notice the stochastic volatilities are mutually independent, this allows us to proceed on an equation-by-equation basis. We draw the stochastic volatility terms using the date-by-date blocking scheme as in Jacquier et al (1994). Note that the scale of the factors is not identified a priori. As in Del Negro and Otrok (2008) we fix the initial value of $H_{t}$ to normalise the scale of the factors.

We generate 50,000 Gibbs sampling replications as described above and discard the first 49,000 as burn-in. The chart below plots recursive means of the first 100 retained draws of some VAR parameters. These vary little suggesting possible evidence for convergence of the MCMC algorithm.

\section{Imposing the sign restrictions}

The sign restrictions are imposed as follows. We compute the structural impact matrix, $A_{0}$, via a slightly modified version of the algorithm recently introduced by Rubio-Ramirez, Waggoner and Zha (2006). Specifically, let $\Omega_{t}=P_{t} P_{t}^{\prime}$ be the Choleski decomposition of the VAR covariance matrix $\Omega_{t}$ (with the foreign variables ordered before the UK variables), and let $\tilde{A}_{0, t} \equiv P_{t}$. We draw a $j \times j$ matrix, $J$, from the $N(0,1)$ distribution, where $j$ denotes the dimension of 'foreign' block in the VAR. We take the $Q R$ decomposition of $J$. That is, we compute the matrices $Q$ and $R$ such that $J=Q R$.

This gives us a candidate structural impact matrix as $A_{0, t}=\tilde{A}_{0, t} \tilde{Q}$, where $\tilde{Q}$ is a $N \times N$ identity matrix with $Q^{\prime}$ in the top $j \times j$ block. Note that such candidate draw has a lower triangular structure for the UK block and, as in the standard Choleski decomposition, implies that UK shocks do not have a contemporaneous impact on the 'foreign' block. If $A_{0, t}$ satisfies the sign restrictions, we keep it and move on to the next Gibbs sample. Otherwise, $J$ is redrawn and the process continues.

\section{Generalised impulse response functions}

Given the time-varying nature of the model, we follow Koop, Pesaran and Potter (1996) in computing the generalised impulse response functions, $\Delta_{t}$, defined as:

$$
\Delta_{t}=E\left(Z_{t+s} \backslash \Psi_{t}, \mu_{i}, Z_{t-1}\right)-E\left(Z_{t+s} \backslash \Psi_{t}, Z_{t-1}\right)
$$


where $\Psi$ denotes all the parameters and hyperparameters of the FAVAR, $Z_{t}$ is the vector of all endogenous variables and $s$ is the horizon under consideration. Equation (A-34) states that the impulse response functions are calculated as the difference between two conditional expectations. The first term denotes a forecast of the endogenous variables conditioned on a shock $\mu_{i}$. The second term is the baseline forecast, ie: conditioned on the scenario where the shock is equal to zero. The conditional expectations in (A-34) are computed via Monte Carlo integration for 500 replications for each Gibbs sampler. Details on the Monte Carlo integration procedure can be found in Koop et al (1996). The forecast error variance decomposition is defined as

$$
F E V D_{t}=\frac{V A R\left(\hat{Z}_{t+s}-Z_{t+s} \backslash \Psi_{t+s}, \mu_{i}\right)}{V A R\left(\hat{Z}_{t+s}-Z_{t+s} \backslash \Psi_{t+s}\right)}
$$

where the term in the denominator denotes the total variance of the forecast error $\hat{Z}_{t+s}-Z_{t+s}$ while the numerator is the variance due to shock $\mu$. As in the case of equation (A-34) Monte Carlo integration is used to compute the forecasts $\hat{Z}_{t+s}$.

\section{Description of the data}

In the interest of brevity we do not provide an exact list of all 560 series in our panel. However this appendix gives an idea of the type of data used and the underlying sources. The full list is available on request from the authors.

\section{International data}

Our international data set contains data on real activity, inflation and interest rates for Australia, Belgium, Canada, Finland, France, Germany, Italy, Japan, Luxembourg, Netherlands, New Zealand, Norway, Portugal, Spain, Sweden and the United States. All data series are seasonally adjusted. We take log differences of all series apart from interest rates. The data is then standardised.

Where available, our real activity data contains real GDP, industrial production, real household consumption expenditure, investment, exports, gross national income and unemployment. In terms of coverage, the United States has the most detailed data with a breakdown of 
unemployment and production by sector. Most of the data is obtained from Datastream and International Financial Statistics (IFS) database. The unemployment data is taken from the Global Financial Database and the US series are obtained from Federal Reserve Economic Data (FRED).

Our basic inflation data contains CPI, GDP deflator, measures of wage growth and import prices. Again, for the United States we are also able to obtain a breakdown of CPI and PPI by sector. The series are obtained from Datastream and IFS.

The international interest rate data primarily contains short-term interest rates. These include discount rates, money market rates, Treasury bill rates and central bank interest rates. The data is obtained from the Global Financial Database.

\section{UK data}

Similar to the international data, our data set on the United Kingdom contains data on real activity and inflation. We also include some indicators of money and key asset prices.

Real activity data includes real GDP, industrial production (with a broad sectoral break down), imports and exports, investment and real household consumption expenditure. The data set includes a very detailed sectoral breakdown of consumption quantities. The data is obtained from the Office for National Statistics (ONS).

Inflation data includes the main price indices (GDP deflator, CPI, RPI and RPIX) and components of the consumption deflator. ONS and the Bank of England are the main sources for the data.

Money data for the United Kingdom includes M0 and M4, with a sectoral breakdown of the latter. This data is obtained from the Bank of England.

The asset price data includes house prices, stock prices, exchange rates (pounds in terms of US dollars, euros, yen, Canadian and Australian dollars) and the term structure of interest rates. The data are obtained from the Global Financial Database and the Bank of England. 


\section{Chart 14: Recursive means of retained MCMC draws}
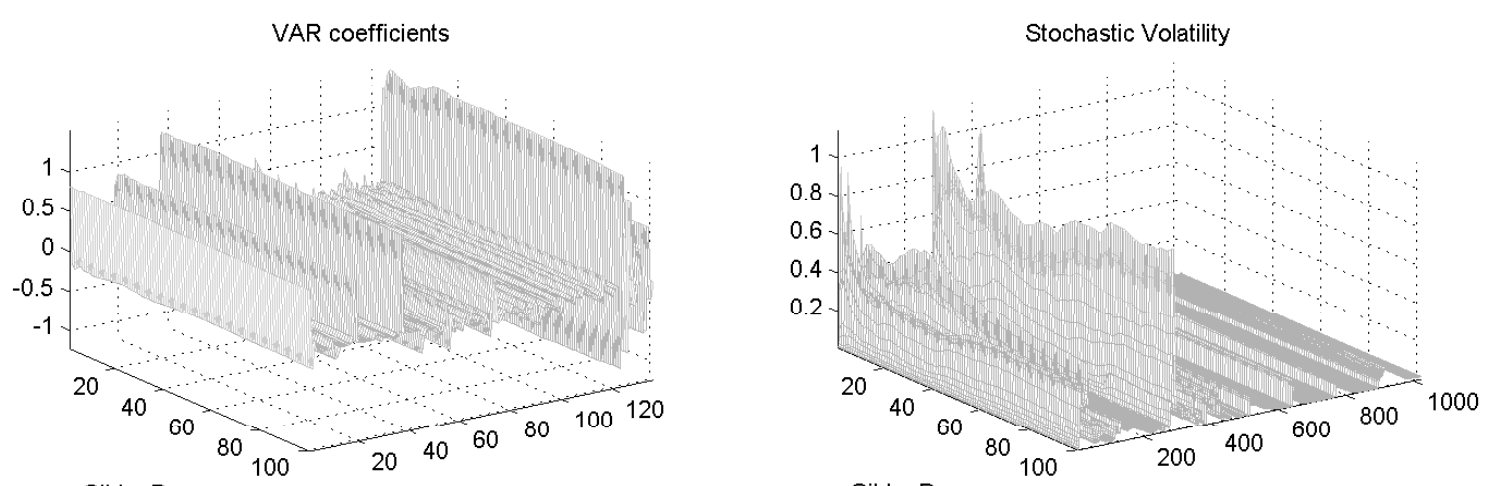

Gibbs Draws

Gibbs Draws

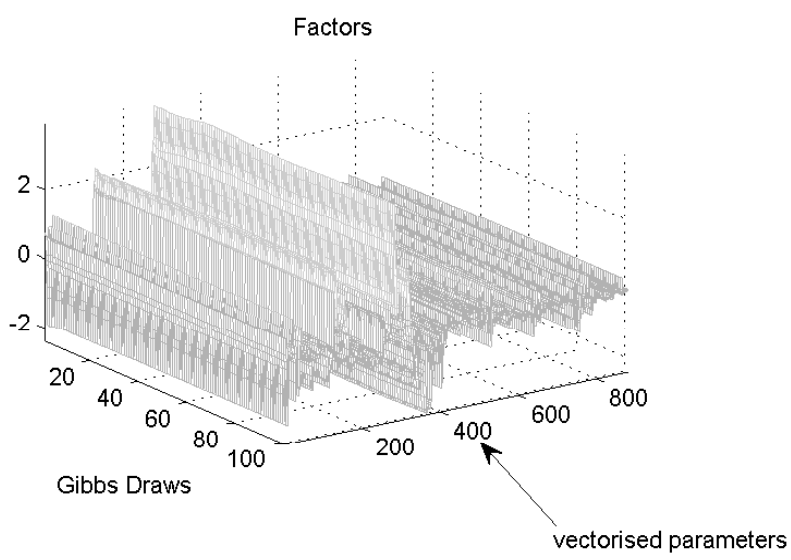




\section{References}

Benati, L (2006), 'UK monetary regimes and macroeconomic stylised facts', Bank of England, Bank of England Working Paper No. 290.

Bernanke, B, Boivin, J and Eliasz, P S (2005), 'Measuring the effects of monetary policy: a factor-augmented vector autoregressive (FAVAR) approach', The Quarterly Journal of Economics, Vol. 120, No. 1, January, pages 387-422.

Betts, C and Devereux, $M$ B (1999), 'The international effects of monetary and fiscal policy in a two country model', in Calvo, G, Dornbusch, R and Obstfeld, M (eds), Essays in Honor of Robert A. Mundell, MIT Press.

Bianchi, F, Mumtaz, $\mathbf{H}$ and Surico, P (2009), 'Dynamics of the term structure of UK interest rates', Bank of England, Bank of England Working Paper No. 363.

Boivin, J and Giannoni, M P (2006), 'Has monetary policy become more effective?', The Review of Economics and Statistics, Vol. 88, No. 3, October, pages 445-62.

Campa, J M and Goldberg, L S (2005), 'Exchange rate pass-through into import prices', The Review of Economics and Statistics, Vol. 87, No. 4, December, pages 679-90.

Campa, J M and Goldberg, L S (2006), 'Pass through of exchange rates to consumption prices: what has changed and why?', National Bureau of Economic Research, Inc, NBER Working Paper No. 12547, Oct.

Canova, F (2005), 'The transmission of US shocks to Latin America', Journal of Applied Econometrics, Vol. 20, No. 2, pages 229-51.

Canova, F and Ciccarelli, M (2006), 'Estimating multi-country VAR models', European Central Bank, European Central Bank Working Paper Series No. 603, Apr.

Carter, C K and Kohn, R (1994), 'On Gibbs sampling for state space models', Biometrika, Vol. 81, No. 3, pages 541-53.

Clarida, R, Galí, J and Gertler, M (2000), 'Monetary policy rules and macroeconomic stability: evidence and some theory', The Quarterly Journal of Economics, Vol. 115, No. 1, February, pages 147-80.

Cogley, T and Sargent, T (2002), 'Evolving post-world war II US inflation dynamics', in Bernanke, B S and Rogoff, K (eds), NBER Macroeconomics Annual 2001, MIT Press.

Cogley, T and Sargent, T J (2005), 'Drift and volatilities: monetary policies and outcomes in the post WWII US', Review of Economic Dynamics, Vol. 8, No. 2, April, pages 262-302. 
Cushman, D O and Zha, T (1997), 'Identifying monetary policy in a small open economy under flexible exchange rates', Journal of Monetary Economics, Vol. 39, pages 433-48.

Del Negro, $M$ and Otrok, $\mathbf{C}$ (2008), 'Dynamic factor models with time-varying parameters: measuring changes in international business cycles', Federal Reserve Bank of New York, Staff Reports No. 326.

Dungey, M and Pagan, A (2000), 'A structural VAR model of the Australian economy', Economic Record, Vol. 76, No. 235, Dec., pages 321-42.

Eichenbaum, M and Evans, C L (1995), 'Some empirical evidence on the effects of shocks to monetary policy on exchange rates', The Quarterly Journal of Economics, Vol. 110, No. 4, November, pages 975-1,009.

Faust, J and Rogers, J H (2003), 'Monetary policy's role in exchange rate behavior', Journal of Monetary Economics, Vol. 50, No. 7, October, pages 1,403-24.

Grilli, V and Roubini, N (1995), 'Liquidity and exchange rates: puzzling evidence from the G-7 countries', New York University, Leonard N. Stern School of Business, Department of Economics, Working Paper No. 95-17, Oct.

Jacquier, E, Polson, N G and Rossi, P E (1994), 'Bayesian analysis of stochastic volatility models', Journal of Business and Economic Statistics, Vol. 12, No. 4, October, pages 371-89.

Kim, C J and Nelson, C R (1998), State-space models with regime-switching: classical and Gibbs-sampling approaches with applications, MIT Press.

Kim, C J and Nelson, C R (1999), 'Has the US economy become more stable? A Bayesian approach based on a Markov-switching model of the business cycle', The Review of Economics and Statistics, Vol. 81, No. 4, November, pages 608-16.

Kim, S (2001), 'International transmission of US monetary policy shocks: evidence from VAR's', Journal of Monetary Economics, Vol. 48, No. 2, October, pages 339-72.

Kim, $\mathbf{S}$ and Roubini, $\mathbf{N}$ (2000), 'Exchange rate anomalies in the industrial countries: a solution with a structural VAR approach', Journal of Monetary Economics, Vol. 45, No. 3, June, pages 561-86.

Koop, G, Pesaran, M H and Potter, S M (1996), 'Impulse response analysis in nonlinear multivariate models', Journal of Econometrics, Vol. 74, No. 1, September, pages 119-47.

Kose, M A, Otrok, C and Whiteman, C H (2003), 'International business cycles: world, region, and country-specific factors', American Economic Review, Vol. 93, No. 4, September, pages $1,216-39$.

Liu, P (2008), 'The role of international shocks in Australia's business cycle', Reserve Bank of Australia, RBA Research Discussion Paper No. 2008-08, Dec. 
Lubik, T and Schorfheide, F (2005), 'A Bayesian look at new open economy macroeconomics', in NBER Macroeconomics Annual 2005, Vol. 20, NBER, MIT Press.

McConnell, M M and Perez-Quiros, G (2000), 'Output fluctuations in the United States: what has changed since the early 1980's?', American Economic Review, Vol. 90, No. 5, December, pages $1,464-76$.

Mumtaz, H, Oomen, $\mathrm{O}$ and Wang, $\mathbf{J}$ (2006), 'Exchange rate pass-through into UK import prices', Bank of England, Bank of England Working Paper No. 312.

Mumtaz, $\mathbf{H}$ and Surico, P (2008), 'The transmission of international shocks: a factor-augmented VAR approach', Journal of Money, Credit and Banking.

Mumtaz, H and Surico, P (2009), 'The transmission of international shocks: a factor-augmented VAR approach', Journal of Money, Credit and Banking, Vol. 41, No. s1, 02, pages $71-100$.

Primiceri, G E (2005), 'Time varying structural vector autoregressions and monetary policy', Review of Economic Studies, Vol. 72, No. 3, July, pages 821-52.

Rogoff, K S (2003), ‘Globalization and global disinflation', Proceedings, pages 77-112.

Rubio-Ramirez, J F, Waggoner, D and Zha, T (2006), 'Markov-switching structural vector autoregressions: theory and application', Society for Computational Economics, Computing in Economics and Finance 2006, No. 69.

Scholl, A and Uhlig, H (2006), 'New evidence on the puzzles: monetary policy and exchange rates', Society for Computational Economics, Computing in Economics and Finance 2006, No. 5. 